Atmos. Chem. Phys., 13, 10733-10753, 2013

www.atmos-chem-phys.net/13/10733/2013/

doi:10.5194/acp-13-10733-2013

(c) Author(s) 2013. CC Attribution 3.0 License.

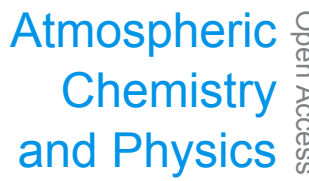

\title{
Uncertainty in modeling dust mass balance and radiative forcing from size parameterization
}

\author{
C. Zhao ${ }^{1}$, S. Chen ${ }^{2,1}$, L. R. Leung ${ }^{1}$, Y. Qian ${ }^{1}$, J. F. Kok ${ }^{3}$, R. A. Zaveri ${ }^{1}$, and J. Huang ${ }^{2}$ \\ ${ }^{1}$ Atmospheric Sciences and Global Change Division, Pacific Northwest National Laboratory, Richland, WA, USA \\ ${ }^{2}$ Key Laboratory for Semi-Arid Climate Change of the Ministry of Education, Lanzhou University, Gansu, China \\ ${ }^{3}$ University of California, Los Angeles, CA, USA
}

Correspondence to: C. Zhao (chun.zhao@pnnl.gov)

Received: 11 July 2013 - Published in Atmos. Chem. Phys. Discuss.: 25 July 2013

Revised: 24 September 2013 - Accepted: 5 October 2013 - Published: 5 November 2013

\begin{abstract}
This study examines the uncertainties in simulating mass balance and radiative forcing of mineral dust due to biases in the dust size parameterization. Simulations are conducted quasi-globally $\left(180^{\circ} \mathrm{W}-180^{\circ} \mathrm{E}\right.$ and $\left.60^{\circ} \mathrm{S}-70^{\circ} \mathrm{N}\right)$ using the WRF-Chem model with three different approaches to represent dust size distribution (8-bin, 4-bin, and 3-mode). The biases in the 3-mode or 4-bin approaches against a relatively more accurate 8-bin approach in simulating dust mass balance and radiative forcing are identified. Compared to the 8-bin approach, the 4-bin approach simulates similar but coarser size distributions of dust particles in the atmosphere, while the 3-mode approach retains more fine dust particles but fewer coarse dust particles due to its prescribed $\sigma_{g}$ of each mode. Although the 3-mode approach yields up to 10 days of longer dust mass lifetime over the remote oceanic regions than the 8-bin approach, the three size approaches produce a similar dust mass lifetime ( 3.2 days to 3.5 days) on quasi-global average, reflecting that the global dust mass lifetime is mainly determined by the dust mass lifetime near the dust source regions.
\end{abstract}

With the same global dust emission $\left(\sim 4600 \mathrm{Tg} \mathrm{yr}^{-1}\right)$, the 8-bin approach produces a dust mass loading of $39 \mathrm{Tg}$, while the 4-bin and 3-mode approaches produce $3 \%(40.2 \mathrm{Tg})$ and $25 \%$ (49.1 Tg) higher dust mass loading, respectively. The difference in dust mass loading between the 8-bin approach and the 4-bin or 3-mode approaches has large spatial variations, with generally smaller relative difference $(<10 \%)$ near the surface over the dust source regions. The three size approaches also result in significantly different dry and wet deposition fluxes and number concentrations of dust. The difference in dust aerosol optical depth (AOD) (a factor of 3) among the three size approaches is much larger than their difference $(25 \%)$ in dust mass loading. Compared to the 8-bin approach, the 4-bin approach yields stronger dust absorptivity, while the 3-mode approach yields weaker dust absorptivity. Overall, on quasi-global average, the three size parameterizations result in a significant difference of a factor of $2 \sim 3$ in dust surface cooling $\left(-1.02 \sim-2.87 \mathrm{~W} \mathrm{~m}^{-2}\right)$ and atmospheric warming $\left(0.39 \sim 0.96 \mathrm{~W} \mathrm{~m}^{-2}\right)$ and in a tremendous difference of a factor of $\sim 10$ in dust TOA (top of atmosphere) cooling $\left(-0.24 \sim-2.20 \mathrm{~W} \mathrm{~m}^{-2}\right)$. The impact of different size representations on dust radiative forcing efficiency is smaller. An uncertainty of a factor of 2 is quantified in dust emission estimation due to the different size parameterizations. This study also highlights the uncertainties in modeling dust mass and number loading, deposition fluxes, and radiative forcing resulting from different size parameterizations, and motivates further investigation of the impact of size parameterizations on modeling dust impacts on air quality, climate, and ecosystems.

\section{Introduction}

Desert dust has been suggested as the main contributor to the global aerosol burden (Forster et al., 2007). Dust plays an important role in the regional and global climate system and has significant impact on air quality (e.g., Woodward et al., 2001; Thomson et al., 2006; Huang et al., 2007; Lau et al., 2009; Zhao et al., 2011, 2012). First, it affects Earth's radiative budget directly through scattering and absorption of radiation (e.g., Sokolik et al., 2001; Balkanski 
et al., 2007; Zhao et al., 2010; Chen et al., 2013) and indirectly by acting as cloud condensation nuclei (CCN) and ice nuclei (IN) and thus impacting clouds and radiation (e.g., DeMott et al., 2010; Creamean et al., 2013). Second, when dust deposits on snow or ice, it would reduce snow/ice reflectance (surface darkening) and consequently change the climate and hydrological cycle by accelerating snow melting (Painter et al., 2010; Qian et al., 2011). Deposition of dust to oceans provides nutrients such as iron to ecosystems and may be important for the ocean uptake of atmospheric $\mathrm{CO}_{2}$ by promoting phytoplankton growth (e.g., Mahowald et al., 2009). Deposition of dust may also influence the ecosystem of rainforests by providing phosphorous as a source of nutrients (e.g., Chadwick et al., 1999). Third, dust is important for air quality through its impact on visibility and concentration of particulate matter, and thus can have negative impacts on human health (e.g., Kim et al., 2001; Chen et al., 2004; Thomson et al., 2006). Furthermore, dust can interact with air pollution through heterogeneous reactions with pollutant gases such as nitric acid and sulfur dioxide (Liao et al., 2003; Bian and Zender, 2003).

There have been increasing efforts to improve dust modeling in the last decades (e.g., Marticorena and Bergametti, 1995; Ginoux et al., 2001; Shao, 2001; Zender et al., 2003; Darmenova et al., 2009; Shao et al., 2010; Zhao et al., 2010; Solomos et al., 2011). Although state-of-the-art models are able to generally capture many observed features of dust distribution, modeling the spatial distribution of dust and its radiative forcing remains uncertain and challenging, as highlighted by Forster et al. (2007). Climate models simulate a very wide range of values for global dust emission and deposition as well as dust loading and its atmospheric lifetime. By comparing results of multiple models, the Aerosol Comparisons between Observations and Models (AEROCOM) project (http://nansen.ipsl.jussieu.fr/ AEROCOM/) showed that models simulate the climatology of dust aerosol optical depth (AOD) within a factor of two whereas the total deposition and surface concentration are reproduced within a factor of 10 (Huneeus et al., 2011). Models simulate global dust emissions between 514 and $4313 \mathrm{Tg} \mathrm{yr}^{-1}$ and dust loads ranging from 6.8 to $29.5 \mathrm{Tg}$ (Textor et al., 2006; Huneeus et al., 2011). Recent studies have started to understand this large variation associated with dust modeling that results from the uncertainties in many model processes, such as dust source and sink processes, size distributions of emitted dust and dust in the atmosphere, and physical and chemical properties of dust (Ginoux et al., 2001; Tegen et al., 2002; Zender et al., 2003; Balkanski et al., 2007; Darmenova et al., 2009; McConnell et al., 2010; Kok, 2011; Zhao et al., 2010, 2011). In addition, the spatial resolution of models may also contribute to the uncertainty of dust modeling (Gläser et al., 2012). However, there is relatively less attention given to the impact of size representation of dust in models.
The size distributions of dust particles in the atmosphere are mainly represented using multiple modes or bins in climate models (Huneeus et al., 2011). A modal approach represents the size distribution of aerosols by several overlapping intervals, called modes, normally assuming a log-normal distribution within each mode, while a bin approach represents the size distribution of aerosols by several discrete size bins, which are defined by their lower and upper dry particle diameters. Generally, a modal approach is less accurate because of its assumption of log-normal distribution and limited number of modes, but it is computationally cheaper than a bin approach that uses more bins. The modal approach is also often further simplified (e.g., assuming a constant standard deviation of the log-normal distributions) and hence has biases in simulating aerosol size distributions (e.g., Zhang et al., 1999; Zhao et al., 2010). Herzog et al. (2004), using a box model, found that a modal approach simulates a difference of $<20 \%$ in number concentrations and surface area density compared to a bin approach. Kokkola et al. (2009) found that sectional and modal approaches simulate significantly different stratospheric conditions perturbed by volcano eruption. Mann et al. (2012) compared the modal and sectional approach in modeling aerosol microphysics using a 3-D global offline chemistry transport model. They found differences in annual mean surface-level masses of sulfate, sea salt, black carbon (BC), and organic carbon (OC) within $25 \%$ in nearly all regions. Although these studies have demonstrated some differences in modeling aerosols between modal and sectional approaches, none of them focused on dust, and the impact of different size representations on simulating dust and its radiative forcing has not yet been investigated.

The sizes of dust particles can range from nanometer to micron; however most climate models represent dust size distribution with a limited number of bins or modes (e.g., 3 or 4) for computational efficiency (Huneeus et al., 2011). Therefore, size representation of dust can be one of the main factors that significantly contribute to uncertainties in modeling dust, particularly over areas far from the main dust source regions. To enhance our understanding of the impact of size representation on the simulation of dust and its radiative forcing, a modeling framework including different size representations (e.g., mode versus bin, and fewer versus more bins) of dust is needed. The WRF-Chem model (Grell et al., 2005), a version of the Weather Research and Forecasting (WRF) model (Skamarock et al., 2008) that simulates trace gases and particulates simultaneously with the meteorological fields, includes different size representations (modal and bin) of aerosols. The model has been used by Zhao et al. (2010) to investigate the sensitivity of the simulated dust radiative forcing to dust emission and size representation schemes over West Africa. Zhao et al. (2010) found that with the 8-bin size approach, WRF-Chem can capture well the observed dust size distribution near the dust source region of the Sahara, and performs better than a 3-mode size representation. In this study, the WRF-Chem model is used 
to conduct quasi-global $\left(-180^{\circ}-180^{\circ} \mathrm{E}, 60^{\circ} \mathrm{S}-70^{\circ} \mathrm{N}\right)$ simulations with three size representations (3-mode, 4-bin, and 8-bin) of dust to investigate the impact of size representation on modeling dust mass balance and its radiative forcing. The paper is organized as follows. Sections 2 and 3 detail the WRF-Chem model and the observations used in this study. The results are discussed in Sect. 4. The paper concludes in Sect. 5.

\section{Model description}

In this study, WRF-Chem (v3.3.1) is used with updates by the Pacific Northwest National Laboratory (PNNL), as described in Sect. 2.1 below. Section 2.2 discusses the setup of the simulations. The emissions used in the simulations including anthropogenic and biomass burning emissions, and online calculated emissions of mineral dust and sea salt are described in Sect. 2.3.

\subsection{WRF-Chem}

Two of the aerosol schemes implemented in WRF-Chem are used. One is the MADE/SORGAM (Modal Aerosol Dynamics Model for Europe and Secondary Organic Aerosol Model) aerosol model (Ackermann et al., 1998; Schell et al., 2001) coupled with the RADM2 (Regional Acid Deposition Model 2) photochemical mechanism (Stockwell et al., 1990). The other is the MOSAIC (Model for Simulating Aerosol Interactions and Chemistry) aerosol model (Zaveri et al., 2008) coupled with the CBM-Z (Carbon Bond Mechanism) photochemical mechanism (Zaveri and Peters, 1999). The MADE/SORGAM aerosol scheme uses the modal approach with three log-normal modes (Aitken, accumulation, and coarse modes) to represent aerosol size distributions, while the MOSAIC aerosol scheme uses the bin approach where the aerosol size distribution is divided into discrete size bins, i.e., four bins or eight bins in the current version of WRF-Chem (Fast et al., 2006). All major aerosol components are simulated in the model, including sulfate $\left(\mathrm{SO}_{4}^{2-}\right)$, nitrate $\left(\mathrm{NO}_{3}^{-}\right)$, ammonium $\left(\mathrm{NH}_{4}^{+}\right)$, elemental carbon (EC), organic matter $(\mathrm{OM})$, sea salt, and mineral dust.

Both aerosol schemes include physical and chemical processes of nucleation, condensation, coagulation, aqueous phase chemistry, water uptake by aerosols, and dry and wet deposition. Although it would be more straightforward to compare the bin and modal size approaches in the same aerosol scheme, neither of the aerosol schemes is implemented with both size approaches in the version (v3.3.1) of WRF-Chem used in this study (the same is true for the newest version (v3.5) of WRF-Chem). In order to treat the source and sink processes of dust consistently, both aerosol schemes are configured with the same aerosol emission and dry and wet deposition modules. The only difference between the two aerosol models is aerosol chemistry that may not play a sig- nificant role in simulating dust life cycle in this study. Therefore the difference between the two aerosol schemes in simulating dust mass loading and radiative forcing is mostly attributable to their different size representations (mode versus bin; discussed in Sect. 4). Aerosol dry deposition is simulated following the approach of Binkowski and Shankar (1995). Wet removal of aerosols by large-scale stratiform cloud includes in-cloud removal (rainout) and below-cloud removal (washout) by impaction and interception for grid-resolved clouds and precipitation following Easter et al. (2004) and Chapman et al. (2009). In this study, convective transport of aerosols by cumulus clouds is coupled with the Kain-Fritsch cumulus scheme (Kain et al., 1990; Kain, 2004) following Zhao et al. (2009), and wet removal of aerosols by cumulus clouds uses the scheme of Liu et al. (2001), which is similar to that of the GEOS-Chem model (Bey et al., 2001).

Aerosol optical properties such as extinction, singlescattering albedo, and asymmetry factor for scattering are computed as a function of wavelength and three-dimensional position. A detailed description of the computation of aerosol optical properties in WRF-Chem can be found in Fast et al. (2006) and Barnard et al. (2010). Aerosol radiative feedback was coupled with the Rapid Radiative Transfer Model (RRTMG) (Mlawer et al., 1997; Iacono et al., 2000) for both shortwave (SW) and longwave (LW) radiation as implemented by Zhao et al. (2011). Aerosol-cloud interactions were included in the model by Gustafson et al. (2007) for calculating the activation and re-suspension between dry aerosols and cloud droplets. Aerosols in this study are assumed internally mixed in each mode or bin, i.e., a complex refractive index is calculated by volume averaging for each mode or bin for each chemical constituent of aerosols. Therefore, in this study, the optical depth and direct radiative forcing of dust are diagnosed following the methodology by Zhao et al. (2013). The refractive index of dust is set to $1.53+0.003$ i globally as Zhao et al. (2010).

\subsection{Numerical experiments}

The WRF-Chem simulations are performed at $1^{\circ}$ horizontal resolution using a quasi-global channel configuration (using periodic boundary conditions in the zonal direction) with $360 \times 130$ grid cells $\left(180^{\circ} \mathrm{W}-180^{\circ} \mathrm{E}, 60^{\circ} \mathrm{S}-70^{\circ} \mathrm{N}\right)$ (Fig. 1). The quasi-global configuration is used instead of global configuration due to some technical difficulties in running global WRF-Chem in v3.3.1. To our best knowledge, global WRFChem has not been used in previous published research. This study is the first to conduct a quasi-global simulation using WRF-Chem. The simulation is configured with 30 vertical layers up to $50 \mathrm{hPa}$. The meteorological initial and lateral boundary (only for the meridional direction) conditions are derived from the National Center for Environmental Prediction final analysis (NCEP/FNL) data at $1^{\circ}$ horizontal resolution and $6 \mathrm{~h}$ temporal intervals. The modeled u-component and v-component wind and atmospheric 
Table 1. Mass balance for dust in WRF-Chem experiments.

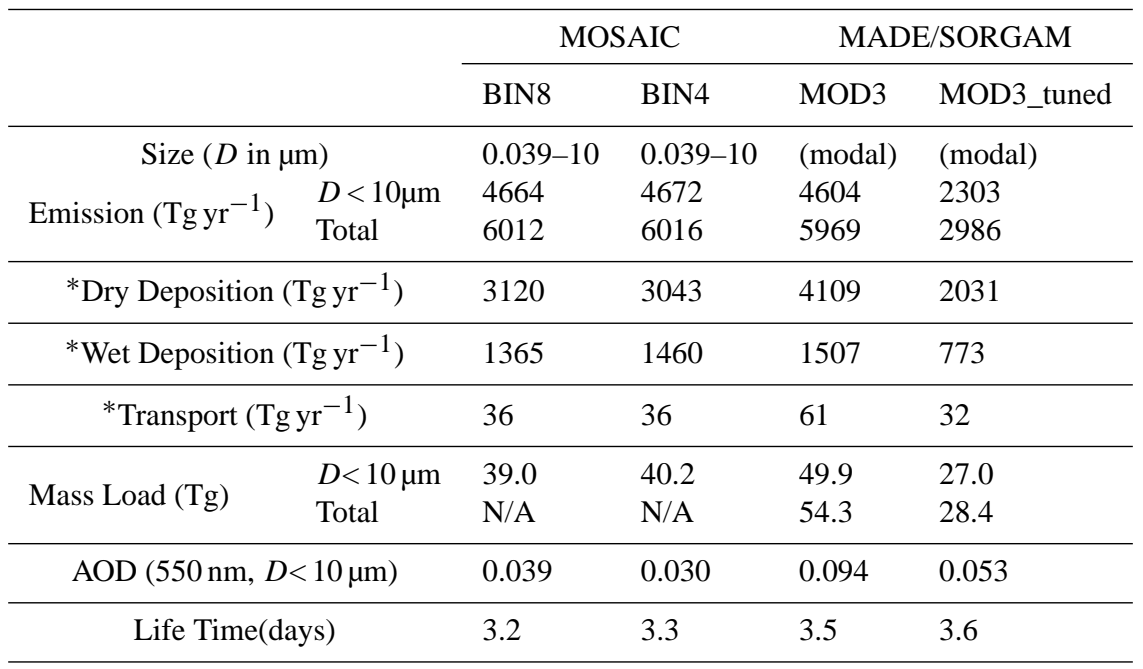

* The dust mass balance contributed by dry deposition, wet deposition, and transport is calculated for dust particles in all size ranges in the MOD3 and MOD3_tuned cases and for dust particles with diameter smaller than $10 \mu \mathrm{m}$ in the BIN8 and BIN4 cases.

\section{$6012 \mathrm{Tg} /$ year}

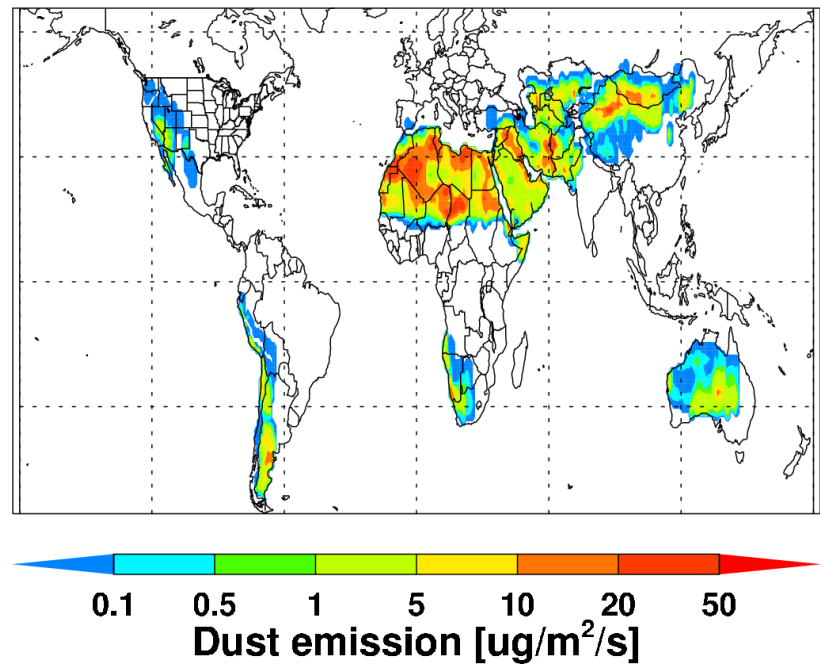

Fig. 1. Spatial distribution of annual mean dust emission in 2011 from the WRF-Chem simulation in the BIN8 case. The value of annual global total dust emission is also shown.

temperature are nudged towards the NCEP/FNL reanalysis data with a nudging timescale of $6 \mathrm{~h}$ in all cases (Stauffer and Seaman, 1990). Nudging provides a better simulation of large-scale circulation, which is important for long-range transport. The chemical initial and boundary (only for the meridional direction) conditions are from the default profiles in WRF-Chem, which are the same as those used by McKeen et al. (2002) and are based on averages of midlatitude aircraft profiles from several field studies over the eastern Pacific Ocean. The impact of chemical boundary con- ditions on the simulated results is found negligible in this study (will be discussed in Sect. 4). The simulation is conducted from 1 December 2010 to 31 December 2011. Only results for the year of 2011 (referred to as the simulation period hereafter) are analyzed to minimize the impact from the initial condition. The MYJ (Mellor-Yamada-Janjic) planetary boundary layer scheme, Noah land surface scheme, Morrison 2-moment microphysics scheme, Kain-Fritsch cumulus scheme, and RRTMG longwave and shortwave radiation schemes are used in this study.

In order to examine the uncertainties in modeling dust mass balance and radiative forcing resulting from size representation, WRF-Chem simulations are conducted for four cases: BIN8, BIN4, MOD3, and MOD3_tuned. BIN8 and BIN4 use the MOSAIC aerosol scheme with the 8-bin and 4-bin size representations, respectively; MOD3 uses the MADE/SORGAM aerosol scheme with the 3-mode size representation; MOD3_tuned is similar to MOD3 except that the total dust emission is tuned to be half of the former three cases (will be discussed in Sect. 2.3 about dust emission). All four case simulations are summarized in Table 1. As mentioned above, a modal or bin approach with a smaller number of modes or bins is less accurate in representing the dust size distribution than a bin approach that uses more bins. To examine the uncertainty in modeling dust mass balance and radiative forcing resulting from size representation, we focus on comparing simulations in the BIN4, MOD3, and MOD3_tuned cases with the BIN8 case, all using the same physics parameterizations of dust. In other words, the BIN8 case is taken as a benchmark for analysis. With nudged meteorology, the radiative feedback of dust on the meteorology is minimized so that the difference in dust mass balance among the four cases results mainly from the direct impact 
of size representations without the feedback of changed meteorology to dust emissions and simulations of other aerosol species. We will note that the simulated dust emission and mass of other aerosol species are similar to each other among the four cases (Sect. 4). The impact of size representations on dust's climatic effect will be investigated in future study.

\subsection{Emissions}

\subsubsection{Dust emission}

The dust emission scheme adopted from the Goddard Chemistry Aerosol Radiation and Transport (GOCART) model (Ginoux et al., 2001) coupled with the MADE/SORGAM and MOSAIC aerosol schemes (Zhao et al., 2010) is used in this study. It was implemented and evaluated by Zhao et al. (2010) over North Africa, and has been further evaluated and used over other regions (e.g., North America, East Asia, and the Arabian Peninsula) by previous studies for dust simulations with WRF-Chem (e.g., Zhao et al., 2011, 2012; Chen et al., 2013; Kalenderski et al., 2013). The GOCART scheme calculates the dust emission flux $G$ as

$G=C S s_{\mathrm{p}} u_{10 \mathrm{~m}}^{2}\left(u_{10 \mathrm{~m}}-u_{\mathrm{t}}\right)$,

where $C\left(\mu \mathrm{g} \mathrm{s}^{2} \mathrm{~m}^{-5}\right)$ is an empirical proportionality constant, $S$ is a source function that defines the potential dust source regions and comprises surface factors, such as vegetation and snow cover, $s_{\mathrm{p}}$ is a fraction of each size class of dust in emission, $u_{10 \mathrm{~m}}\left(\mathrm{~m} \mathrm{~s}^{-1}\right)$ is the horizontal wind speed at $10 \mathrm{~m}$, and $u_{\mathrm{t}}\left(\mathrm{m} \mathrm{s}^{-1}\right)$ is the threshold $10 \mathrm{~m}$ wind speed below which dust emission does not occur and is a function of particle size, air density, and surface moisture. The source function $S$ is prescribed as in Ginoux et al. (2001). The default value of $C$ is $1.0 \mu \mathrm{g} \mathrm{s}^{2} \mathrm{~m}^{-5}$ provided by Ginoux et al. (2001). With this $C$ value, the MOD3 simulation significantly overestimates the AOD over the dust source regions compared to satellite retrievals (see further discussion in Sect. 4). Since the $C$ value is tunable, we use a $C$ value of $0.5 \mu \mathrm{g} \mathrm{s}^{2} \mathrm{~m}^{-5}$ in the MOD3_tuned case so that the simulated mean AOD with the modal size representation is more consistent with the satellite retrievals over the dust source regions. Comparing the result of the MOD3_tuned case with that of the BIN8 case, we can identify the uncertainties in simulating dust mass balance and radiative forcing when the mode size representation is used in models where dust emissions are calibrated to simulate reasonable dust AOD against observations. Note that the GOCART scheme is only used for calculating total dust emission fluxes, and the emitted dust particles follow the size distributions discussed below.

The vertical dust flux emitted in each grid box and time step is distributed using the corresponding size representations of the four cases. The size distributions of emitted dust in all four cases are made consistent, so that the difference in simulated dust size distributions results solely from the difference in size representations (see further discussion in
Sect. 4). The size distribution of emitted dust follows a theoretical expression based on the physics of scale-invariant fragmentation of brittle materials derived by Kok (2011). In the BIN8 case, dust particles are emitted into eight size bins (0.039-0.078 $\mu \mathrm{m}, 0.078-0.156 \mu \mathrm{m}, 0.156-0.312 \mu \mathrm{m}, 0.312-$ $0.625 \mu \mathrm{m}, 0.625-1.25 \mu \mathrm{m}, 1.25-2.5 \mu \mathrm{m}, 2.5-5.0 \mu \mathrm{m}$, and 5.0$10.0 \mu \mathrm{m}$ dry diameter) with mass fractions of $10^{-6} \%$, $10^{-4} \%, 0.02 \%, 0.2 \%, 1.5 \%, 6 \%, 26 \%$, and $45 \%$, respectively. In the BIN4 case, dust particles are emitted into four size bins $(0.039-0.156 \mu \mathrm{m}, 0.156-0.625 \mu \mathrm{m}, 0.625-$ $2.5 \mu \mathrm{m}$, and $2.5-10.0 \mu \mathrm{m}$ dry diameter) with mass fractions of $10^{-4} \%, 0.22 \%, 7.5 \%$, and $71 \%$, respectively. In both MOD3 and MOD3_tuned cases, the dust particles are emitted into two log-normal modes (accumulation and coarse) with mass fraction of $15 \%$ and $85 \%$, respectively. The volume median diameter $\left(\mathrm{d}_{\mathrm{pgv}}\right)$ and the standard deviation $\left(\sigma_{g}\right)$ of the two log-normal modes are $2.91 \mu \mathrm{m}$ and 2.20, respectively, for the accumulation mode, and $6.91 \mu \mathrm{m}$ and 1.73 , respectively, for the coarse mode. The dust mass and number concentrations in each bin or mode are updated during the simulations. In simulations with mode size representation, the volume mean diameters of each mode are also updated from the predicted mass and number concentrations, while the prescribed $\sigma_{g}$ are kept constant, which is one of the major factors contributing to the biases of the modal approach to represent dust size distributions (Zhao et al., 2010).

It is noteworthy that the MOD3 and MOD3_tuned cases simulate dust particles in the entire modes, while the BIN8 and BIN4 cases simulate dust particles with a diameter smaller than $10 \mu \mathrm{m}(D<10 \mu \mathrm{m})$. One reason is that particles larger than $10 \mu \mathrm{m}$ in diameter generally have short atmospheric lifetimes due to gravitational settling (Tegen and Fung, 1994). In addition, this study finds that the mass of dust particles larger than $10 \mu \mathrm{m}$ in diameter contributes to $<10 \%$ of total dust mass loading based on the MOD3 and MOD3_tuned simulations. Therefore, the BIN8 and BIN4 cases only simulate $\sim 80 \%$ of the total dust emissions to keep the same size distributions of emitted dust with that of MOD3 and MOD3_tuned. When the model simulated dust mass loading and radiative forcing among the four cases compared in the following, for consistency, only the contribution of dust particles smaller than $10 \mu \mathrm{m}$ dry diameter is considered.

\subsubsection{Other emissions}

Anthropogenic emissions are obtained from the Reanalysis of the TROpospheric (RETRO) chemical composition inventories (http://retro.enes.org/index.shtml) except over East Asia and the United States, where anthropogenic emissions are from David Streets' 2006 emission inventory (Zhang et al., 2009) and from the US National Emission Inventory (NEI) 2005 (WRF-Chem user guide from http://ruc.noaa.gov/wrf/WG11/Users_guide.pdf), respectively. Biomass burning emissions are obtained from 
the Global Fire Emissions Database version 3 (GFEDv3), with monthly temporal resolution (van der Werf et al., 2010) and vertically distributed following the injection heights suggested by Dentener et al. (2006) for the Aerosol InterComparison project (AeroCom). Sea salt emission follows Zhao et al. (2013), which is based on Gong (2003) to include correction of particles with radius smaller than $0.2 \mu \mathrm{m}$ and Jaeglé et al. (2011) to include the sea salt emission dependence on sea surface temperature.

\section{Observations}

The AOD retrieved from the Moderate Resolution Imaging Spectroradiometer (MODIS) instruments on board the NASA Terra and Aqua platforms and the Multi-angle Imaging SpectroRadiometer (MISR) instrument on board the NASA Terra platform are used. MODIS is uniquely designed with high spatial resolution, wide spectral range, and near daily global coverage to monitor changes in the Earth system, including tropospheric aerosols (Kaufman et al., 1997). The standard MODIS aerosol product does not retrieve aerosol information over bright surfaces (e.g., the Sahara) due to a strong surface spectral contribution in the visible range (Kaufman et al., 1997). A new algorithm, called the "deep blue algorithm" (Hsu et al., 2006), integrated with the existing MODIS algorithm can retrieve AOD even over bright surfaces. In this study, the retrieved "deep blue" AOD from MODIS (L3) is used over land, while the standard retrieved AOD is used over the ocean. The MODIS on board the Aqua platform passes over the Equator at 13:30 LT (local time) during daytime (Kaufman et al., 1997). MISR observes continuously in four narrow spectral bands centered at 446, 558, 672 , and $866 \mathrm{~nm}$ and at nine distinct zenith angles, ranging from $70^{\circ}$ afterward to $70^{\circ}$ forward. MISR's spectral data and unique blend of directional allows aerosol retrieval algorithms that do not depend on the explicit radiometric surface properties. As such, MISR can retrieve aerosol properties even over highly reflective surfaces like deserts (Diner et al., 1998; Martonchik et al., 2004). The MISR on board the Terra platform passes over the Equator at $\sim 10: 45$ LT during daytime (Diner et al., 2001). When compared to the MODIS and MISR retrieved AOD, the model results are sampled from 10:00-14:00 LT for averaging and at the locations where retrievals are available.

\section{Results and discussion}

\subsection{Impact of size representation on dust emission estimation}

Using the experimental design discussed above, the three cases of BIN8, BIN4, and MOD3 have consistent total amounts and spatial distributions of dust emissions. Figure 1 shows the spatial distribution of annual mean dust emission from the WRF-Chem simulations in the BIN8 case in 2011. The model simulates significant amounts of dust emission over major deserts such as Sahara, Taklimakan, Gobi, North American, and Australian deserts. The difference of total dust emissions among these three cases is less than $1 \%$. The annual total global dust emission simulated by the three cases is about $6000 \mathrm{Tg} \mathrm{yr}^{-1}$. The emitted mass of dust particles with diameter sizes smaller than $10 \mu \mathrm{m}$ is $4600 \mathrm{Tg} \mathrm{yr}^{-1}$, which is near the higher end of the range (3995-4313 $\mathrm{Tg} \mathrm{yr}^{-1}$ ) reported by Huneeus et al. (2011). This value is about $50 \%$ higher than $3157 \mathrm{Tg} \mathrm{yr}^{-1}$ estimated by the GOCART model for year 2000 (Huneeus et al., 2011) and $\sim 3000 \mathrm{Tg} \mathrm{yr}^{-1}$ estimated by Mian Chin et al. (2009) and and Kim et al. (2013, this issue) for 2000-2007 using the GOCART model. Although this study uses a similar dust emission scheme as used in the GOCART model, the simulated meteorological fields (e.g., surface winds) and land surface conditions (e.g., soil moisture) could be different between WRF-Chem and the GOCART model. A full investigation of the difference between WRF-Chem and GOCART in simulating dust emission is beyond the scope of this study.

Figure 2 shows the spatial distributions of annual mean AOD at $550 \mathrm{~nm}$ from MISR and MODIS satellite retrievals and the corresponding WRF-Chem simulations in 2011 in the BIN8, BIN4, MOD3, and MOD3_tuned cases. Wind circulations at $700 \mathrm{hPa}$ from the reanalysis data and the WRFChem simulations are also shown. All four cases simulate similar winds and reproduce the circulation pattern in the reanalysis data due to the nudging. Since the overpass times of Terra (MISR) and Aqua (MODIS) are 10:45 LT and 13:45 LT, respectively, the model results are sampled from 10:00-14:00 LT for averaging. The BIN8 and BIN4 cases generally capture well the spatial pattern and magnitude of satellite retrieved AOD, showing high values (up to 1.0) over deserts and polluted regions. It is noteworthy that, although the BIN4 case only uses half the number of bins to represent the size distribution of dust, it produces similar distribution of AOD as the BIN8 case. With the same amount and size distribution of emitted dust, the MOD3 case significantly overestimates AOD near the dust source regions. As we discussed above, another case (MOD3_tuned) with the same size representation as MOD3 but half of total dust emission (i.e., $\sim 3000 \mathrm{Tg} \mathrm{yr}^{-1}$ in total and $2400 \mathrm{Tg} \mathrm{yr}^{-1}$ for dust particles with diameter smaller than $10 \mu \mathrm{m}$ ) is also conducted. The positive bias of AOD in the MOD3 case is significantly reduced in the MOD3_tuned case. The MOD3_tuned case produces similar spatial distribution of AOD compared to the BIN8 case over the dust source regions. This indicates that if dust emission is estimated using the top-down method (i.e., using satellite retrievals to constrain model simulated dust AOD, which is commonly used by the modeling community), it may have an uncertainty of a factor of 2 solely due to the size representations (3-mode versus 8-bin here). This further indicates the complication in comparing the dust 

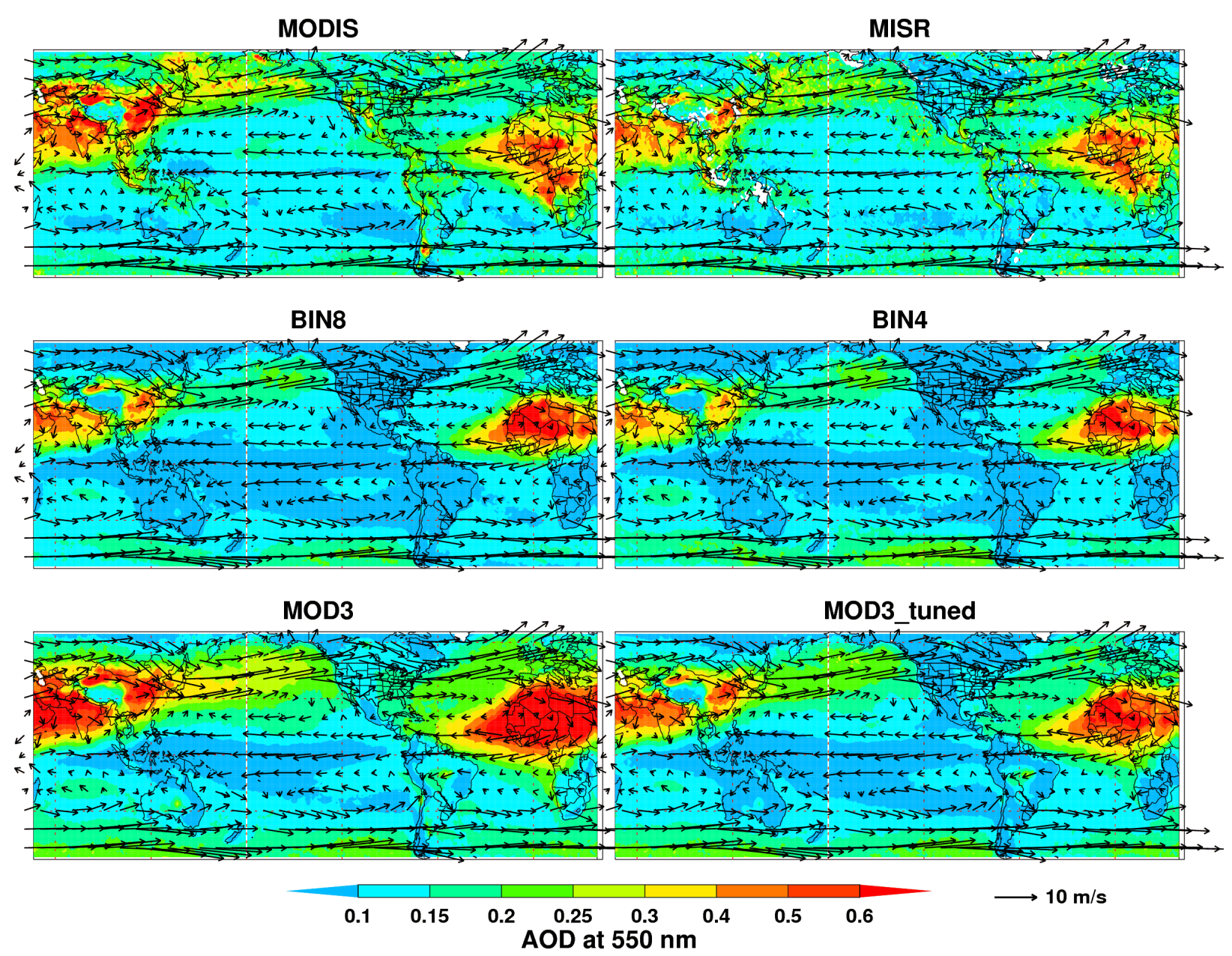

Fig. 2. Spatial distribution of annual mean AOD from the MODIS and MISR retrievals and the corresponding WRF-Chem simulations in the four cases (BIN8, BIN4, MOD3, and MOD3_tuned) in 2011. The model results are sampled between 10:00-14:00 LT at each grid point. The winds at $700 \mathrm{hPa}$ over MODIS and MISR are from GFS reanalysis and over the four cases are from WRF-Chem simulations.

emissions from different models with different size representations.

The AOD diversity among the four cases primarily comes from their difference in simulating dust instead of other aerosol species. Figure 3 shows the spatial distributions of annual mean AOD at $550 \mathrm{~nm}$ contributed by dust and other aerosols, respectively, from the WRF-Chem simulations in 2011 in the BIN8, BIN4, MOD3, and MOD3_tuned cases. In general, dust contributes to $>90 \%$ of total AOD over the desert regions. Over the oceans downwind of the source regions, the dust contribution to total AOD can reach $70 \%$ over the North Atlantic. Its contribution is much less $(\sim 20 \%)$ over the North Pacific due to the strong anthropogenic pollution outflow from East Asia and sea salt emissions. It shows that the difference in total AOD among the cases of BIN8, BIN4, MOD3, and MOD3_tuned is dominated by the difference in dust AOD among the four cases. The BIN8, BIN4, MOD3, and MOD3_tuned cases simulate domainaveraged dust AOD of 0.039, 0.030, 0.094, and 0.053, re- spectively. The BIN8, BIN4, and MOD3_tuned cases simulate much lower domain-averaged dust AOD than MOD3. Although the domain-averaged dust AOD from the BIN8, BIN4, and MOD3_tuned cases also have a large difference (up to $\sim 35 \%$ ), these three cases simulate similar dust AOD over the desert regions with a relative difference of less than $10 \%$.

Although the simulated AOD contributed by other aerosols in the four cases is not the same, its difference is relatively small compared to the difference in the simulated dust AOD. The minor difference among the four cases in simulating other aerosols likely comes from their different mechanisms of aerosol chemistry (MADE/SORGAM versus MOSAIC). However, the difference in aerosol chemistry should only have a minor impact on dust simulation, since the dust mass balance is mainly determined by the emission and the dry and wet deposition processes. The size representations may also affect the simulations of other aerosols. Moreover, although meteorology fields are nudged to the 


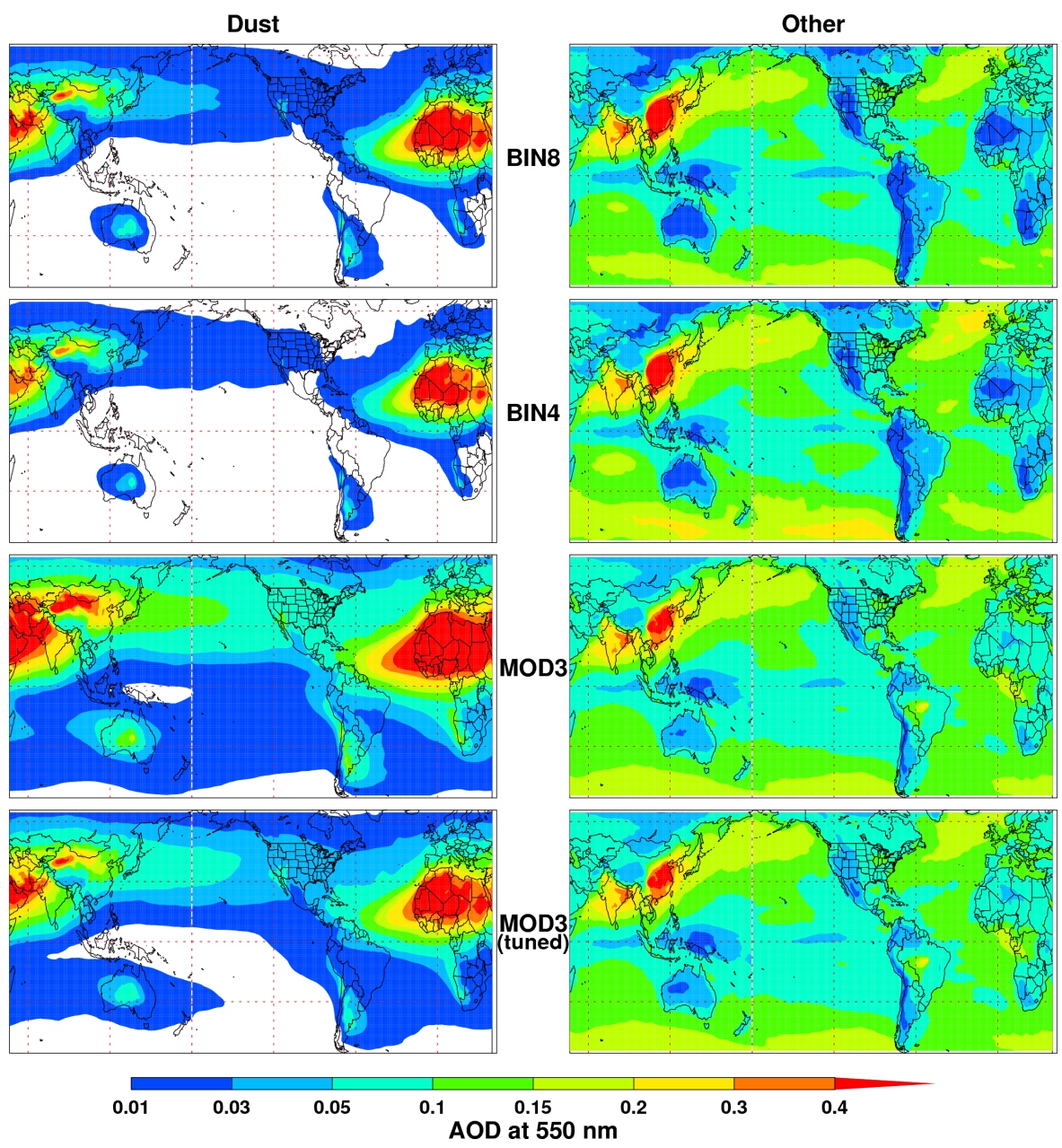

Fig. 3. Spatial distribution of annual mean AOD contributed by dust and other aerosols, respectively, from the WRF-Chem simulations in the four cases (BIN8, BIN4, MOD3, and MOD3_tuned) in 2011.

reanalysis data, the different feedbacks on meteorology from dust radiative forcing among the four cases (Sect. 4.3) may also play a role in the chemistry of other aerosols. Since our primary interest is not in the small difference in simulating other aerosols among the four cases, we focus on the analysis of the impact of size representations on dust simulation hereafter.

\subsection{Impact of size representation on dust mass balance}

\subsubsection{Dust mass loading}

Figure 4 shows the spatial distribution of annual mean dust mass loading in 2011 from the WRF-Chem simulations in the BIN8 case and the difference in the BIN4, MOD3, and MOD3_tuned cases from the BIN8 case. The spatial distribution of dust mass loading in the BIN8 case is consistent with its dust AOD (Fig. 3). A large amount of dust loading is simulated over the source regions (i.e., deserts of the globe). The dust mass loading over the Northern Hemisphere is much larger than over the Southern Hemisphere. It also shows that dust transport affects remote areas downwind of the source regions, such as the North Pacific and North Atlantic, where the dust mass loading can reach $0.1 \mathrm{~g} \mathrm{~m}^{-2}$ and $0.5 \mathrm{~g} \mathrm{~m}^{-2}$, respectively. The annual domain-averaged dust mass loading in the BIN8 case is $39 \mathrm{Tg}$.

The difference of dust mass loading in the BIN4, MOD3, and MOD3_tuned cases from the BIN8 case is calculated by subtracting the dust mass loading in the BIN8 case from that in each of the other three cases. With the same dust emission as BIN8, both BIN4 and MOD3 simulate higher dust mass loading than BIN8 over most regions, with annual domain averages of $40.2 \mathrm{Tg}$ and $49.1 \mathrm{Tg}$, respectively. It is noteworthy that the relative difference in dust mass loading among the BIN8, BIN4, and MOD3 cases is significantly lower than that in dust AOD. The highest difference is located at the desert regions due to the highest dust mass loading there. The relative difference ( $<10 \%$ globally) between BIN4 and BIN8 is much smaller than that (up to $150 \%$ ) 

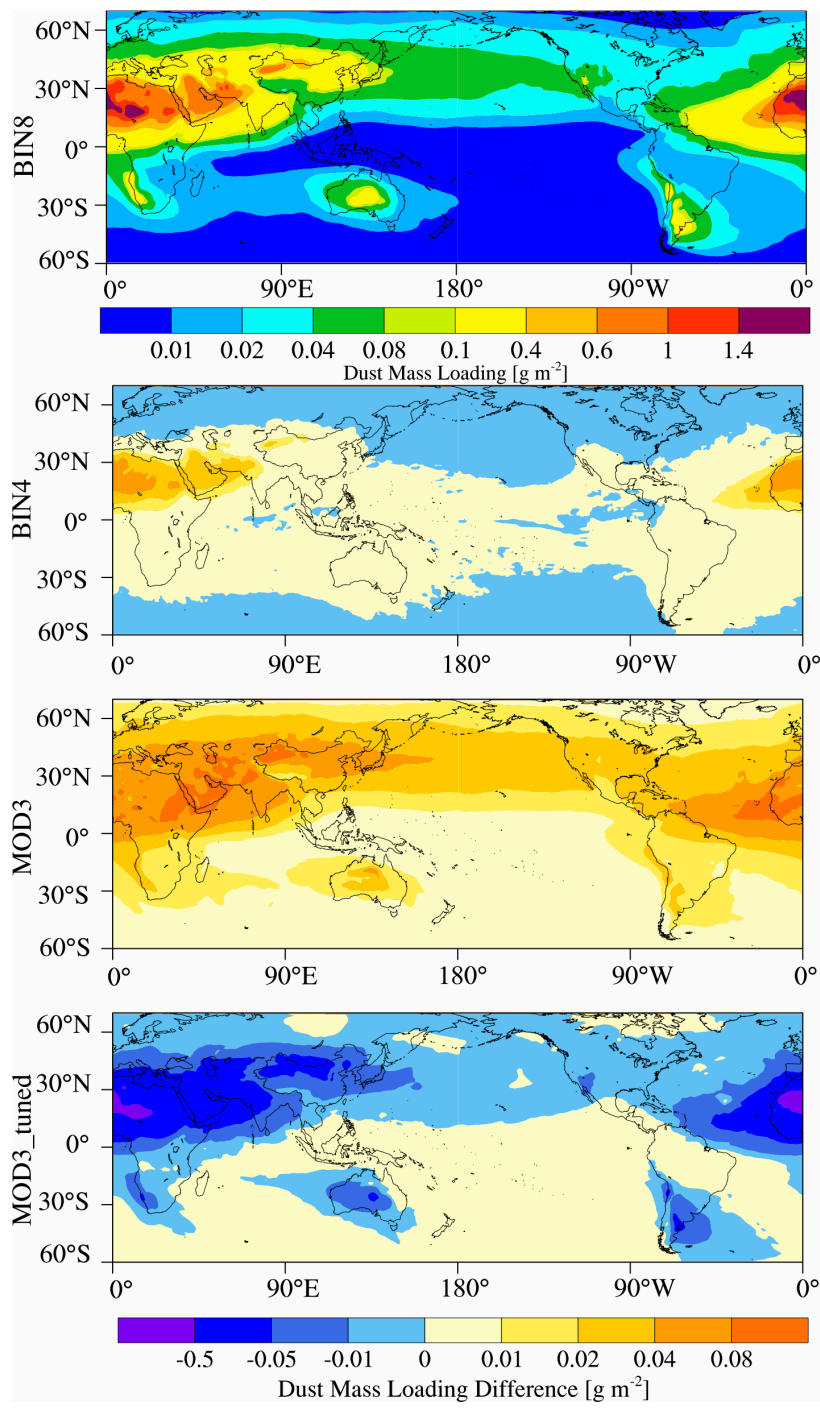

Fig. 4. Spatial distribution of annual mean dust mass loading from the WRF-Chem simulations in the case BIN8 in 2011 (top panel) and the difference in the cases BIN4, MOD3, and MOD3_tuned from BIN8 (three bottom panels).

between MOD3 and BIN8. Over the source regions such as the Sahara and the Taklimakan Desert, the relative difference between MOD3 and BIN8 is within 10\%, which is consistent with Zhao et al. (2010). However, over the downwind regions such as the East China Sea, the relative difference between MOD3 and BIN8 increases to $40 \%$. This difference can even reach $80 \%$ over the eastern and western coasts of the United States after long-range transport and $100 \%$ over the southern oceans where the dust mass loading is relatively low. With half the amount of dust emission in the BIN8 case, the MOD3_tuned case simulates much lower annual domain-averaged dust mass loading $(27 \mathrm{Tg}$ ) than BIN8. The MOD3_tuned case simulates about half of the dust mass loading from the BIN8 case over the desert regions, while it produces similar (with $<10 \%$ relative difference) dust mass loading as the BIN8 case over the Northern Hemisphere and higher (up to $40 \%$ ) dust mass loading over the Southern Hemisphere. It is interesting to note that the MOD3_tuned case with half the amount of dust emission yields $30 \%$ lower annual domain-averaged dust mass loading but $35 \%$ higher dust AOD compared to the BIN8 case. The dust emission, mass loading, and AOD for the four cases are listed in Table 1 . In the analysis and comparison above, only dust particles with a smaller than $10 \mu \mathrm{m}$ dry diameter are considered. However, Table 1 also lists the dust emission and mass loading for all-size dust particles for the cases of MOD3 and MOD3_tuned. It shows that the mass loading of dust with smaller than $10 \mu \mathrm{m}$ dry diameter is about $5 \%$ less than that of all-size dust from the MOD3 and MOD3_tuned simulations.

Figure 5 shows the longitude-height cross section of annual meridional mean dust mass concentration in 2011 from the WRF-Chem simulations in the BIN8 case and the difference in the BIN4, MOD3, and MOD3_tuned cases from the BIN8 case. The result from the BIN8 case shows the highest dust mass concentration $\left(\sim 70 \mu \mathrm{g} \mathrm{m}^{-3}\right)$ over the regions within $\pm 30^{\circ}$ E, where the Sahara, the world largest desert, is located. It also clearly indicates the distribution of global deserts with relatively high dust mass concentration, such as North American deserts around $115^{\circ} \mathrm{W}$ and Central Asian deserts at $60^{\circ}-70^{\circ} \mathrm{E}$. Above the source regions, the dust concentration decreases gradually with height and reaches about $10 \%$ of the surface concentration at $8 \mathrm{~km}$. Over the remote regions, the largest dust mass concentration $\left(\sim 4 \mu \mathrm{g} \mathrm{m}^{-3}\right)$ is found at $3-4 \mathrm{~km}$. In general, BIN4 and MOD3 simulate higher dust mass concentration throughout the atmospheric column. The difference between BIN8 and BIN4 is relatively small $(<10 \%)$. The relatively large difference (up to $\sim 8 \mu \mathrm{g} \mathrm{m}^{-3}$ ) between MOD3 and BIN8 occurs over the source regions in the lower atmosphere $(<\sim 4 \mathrm{~km})$. However, the relative difference between these two cases has the smallest values $(<10 \%)$ near the surface of the source regions. It increases with height and the distance downwind and reaches $100 \%$ over the remote regions (e.g., around $150^{\circ} \mathrm{W}$ ) up to $4 \mathrm{~km}$. The MOD3_tuned case simulates about 30-50\% lower dust concentration over the source regions $\left(60^{\circ} \mathrm{W}-0^{\circ}-\right.$ $\left.100^{\circ} \mathrm{E}\right)$ up to $4 \mathrm{~km}$. Over the remote regions $\left(150^{\circ} \mathrm{E}-180^{\circ}-\right.$ $90^{\circ} \mathrm{W}$, except the North American deserts around $115^{\circ} \mathrm{W}$ ), the MOD3_tuned case simulates about 10-20\% higher dust concentration up to $4 \mathrm{~km}$. At $4-8 \mathrm{~km}$, the relative difference between MOD3_tuned and BIN8 is relatively small $(<20 \%)$. Above $8 \mathrm{~km}$ over the source regions, the MOD3_tuned case simulates again $50 \%$ lower dust concentration.

\subsubsection{Dust size distribution in the atmosphere}

The difference in dust mass loading among the cases of BIN8, BIN4, and MOD3 primarily results from their different dust size distributions. Figure 6 shows the normalized 

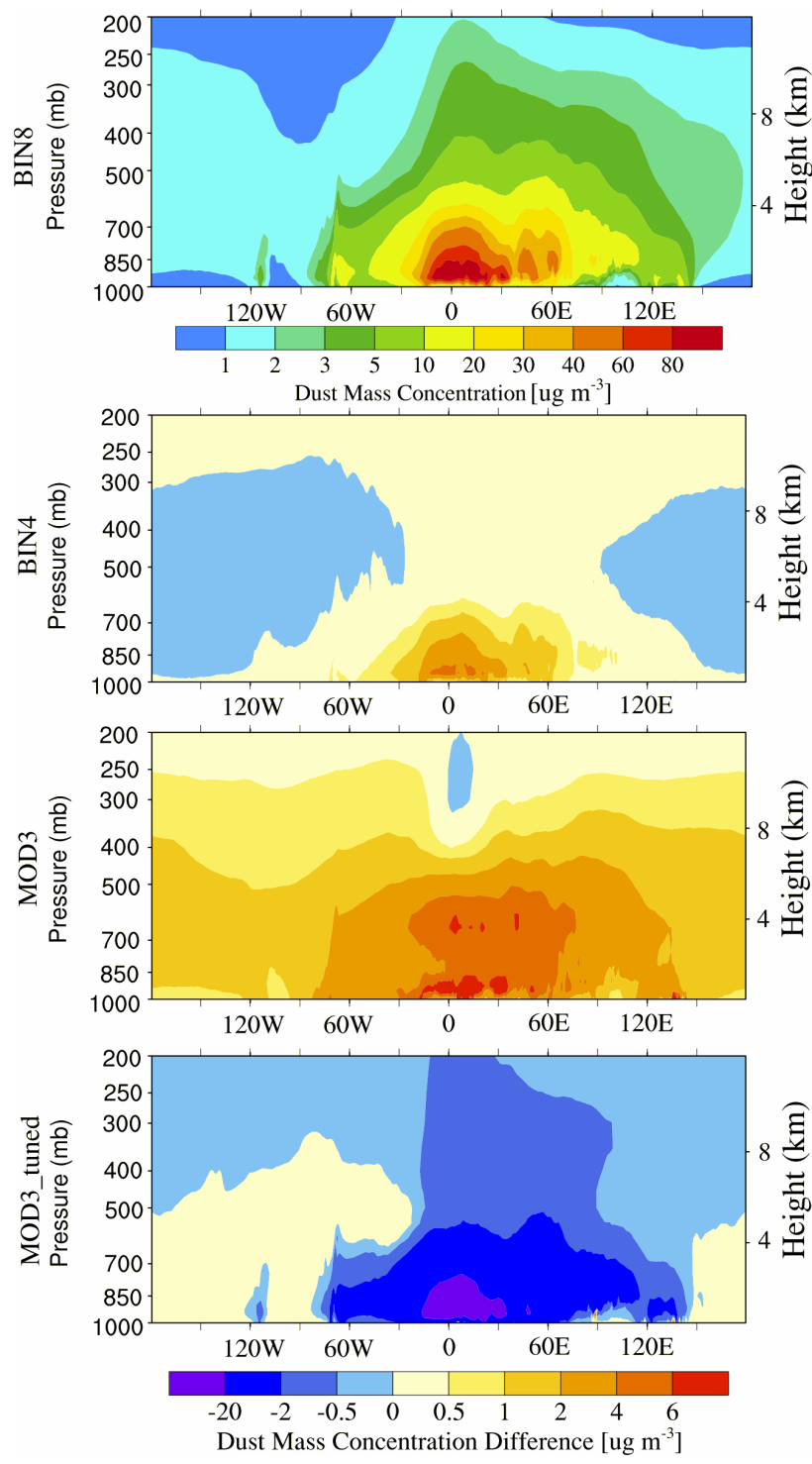

Fig. 5. Cross section of meridional mean dust mass concentration from the WRF-Chem simulations in the case BIN8 in 2011; and the difference in the cases BIN4, MOD3, and MOD3_tuned from the BIN8 case.

size distributions of dust at emission, over the source region (North Africa, $2.5^{\circ} \mathrm{E}-28.5^{\circ} \mathrm{E}$ and $14.5^{\circ} \mathrm{N}-28.5^{\circ} \mathrm{N}$ ), and over the remote region (North Atlantic, $60^{\circ} \mathrm{W}-34.5^{\circ} \mathrm{W}$ and $16.5^{\circ} \mathrm{N}-31.5^{\circ} \mathrm{N}$ ) from the WRF-Chem simulations in the cases of BIN8, BIN4, MOD3, and MOD3_tuned. The dust size distributions over the source and remote regions are column integrated above $1 \mathrm{~km}$. It can be noted that the size distributions of dust at emission are prescribed to be consistent among the four cases as discussed above. The dust size distribution in the BIN4 case generally follows that in the BIN8 case but has coarser size resolution. The MOD3_tuned case simulates similar size distribution with the MOD3 case. The small difference between MOD3 and MOD3_tuned is

likely due to the feedbacks from their different dust mass loading.

Between the cases of BIN8 and MOD3, the dust size distributions start to differentiate in the atmosphere over the source region, and the difference is enlarged after long-range transport over the remote region. The MOD3 case retains substantially more fine dust but less coarse dust versus the BIN8 case, indicating that it simulates a smaller dry deposition rate for fine particles but a larger dry deposition rate for coarse particles, compared to the BIN8 case. This bias is general for a modal size representation with prescribed $\sigma_{g}$ that should be updated during the simulations, since dry deposition generally has a larger rate for coarse particles than for fine particles and thus change the shape of log-normal size distributions that is described by $\sigma_{g}$. Sensitivity tests by Zhao et al. (2010) showed that the dust size distribution is sensitive to the prescribed $\sigma_{g}$ for the mode size representation. This study confirms that the prescribed $\sigma_{g}$ causes the error in calculating dust size distribution using the mode size representation. A three-moment aerosol size parameterization (i.e., predicting aerosol mass, number, and surface area and thus $\sigma_{g}$ ) may be needed for the mode approach to appropriately represent dust size distributions (Binkowski and Roselle, 2003).

The bias in simulating dust size distributions (i.e., overestimating fine particles and underestimating coarse particles) by the MOD3 and MOD3_tuned cases can also be demonstrated by the mass ratio of dust particles with dry diameters $<2.5 \mu \mathrm{m}$ and those with dry diameters $<10 \mu \mathrm{m}$ (i.e., mass ratio of $\mathrm{PM}_{2.5}$-Dust and $\mathrm{PM}_{10}$-Dust). Figure 7 shows the spatial distribution of $\mathrm{PM}_{2.5}$-Dust to $\mathrm{PM}_{10}$-Dust mass ratio in 2011 from the WRF-Chem simulations in the BIN8 case and the difference in the cases of BIN4, MOD3, and MOD3_tuned from the BIN8 case. It clearly shows the transformation of mass ratio of fine and coarse particles during the transport in the BIN8 case. The mass ratio of $\mathrm{PM}_{2.5^{-}}$ Dust $/ \mathrm{PM}_{10}$-Dust is around 0.2 over the desert regions and increases to around 0.35 over the remote regions such as the North Pacific and Atlantic. In general, this ratio has larger values over the Northern Hemisphere than those over the Southern Hemisphere. In general, BIN4 simulates smaller ratio of $\mathrm{PM}_{2.5}$-Dust / $\mathrm{PM}_{10}$-Dust than BIN8. The difference between BIN4 and BIN8 is relatively small within the range of \pm 0.05 . The relative difference between BIN4 and BIN8 is within $\pm 5 \%$ over the desert regions and can reach $-15 \%$ over the remote oceans such as the North Pacific and Atlantic. In contrast, the difference between MOD3 and BIN8 is much larger. MOD3 generally simulates higher values of $\mathrm{PM}_{2.5}$-Dust $/ \mathrm{PM}_{10}$-Dust than BIN8 globally. The difference between MOD3 and BIN8 is smaller over the desert regions $(\sim 0.05)$ than the remote regions (up to $\sim 0.4$ ). The ratio of $\mathrm{PM}_{2.5}$-Dust $/ \mathrm{PM}_{10}$-Dust simulated by MOD3 can reach $\sim 0.6$ over the remote oceans, which is a factor of 2 of that from BIN8. Near the desert regions, MOD3 simulates a $30-50 \%$ higher ratio of $\mathrm{PM}_{2.5}$-Dust / $\mathrm{PM}_{10}$-Dust than BIN8. 

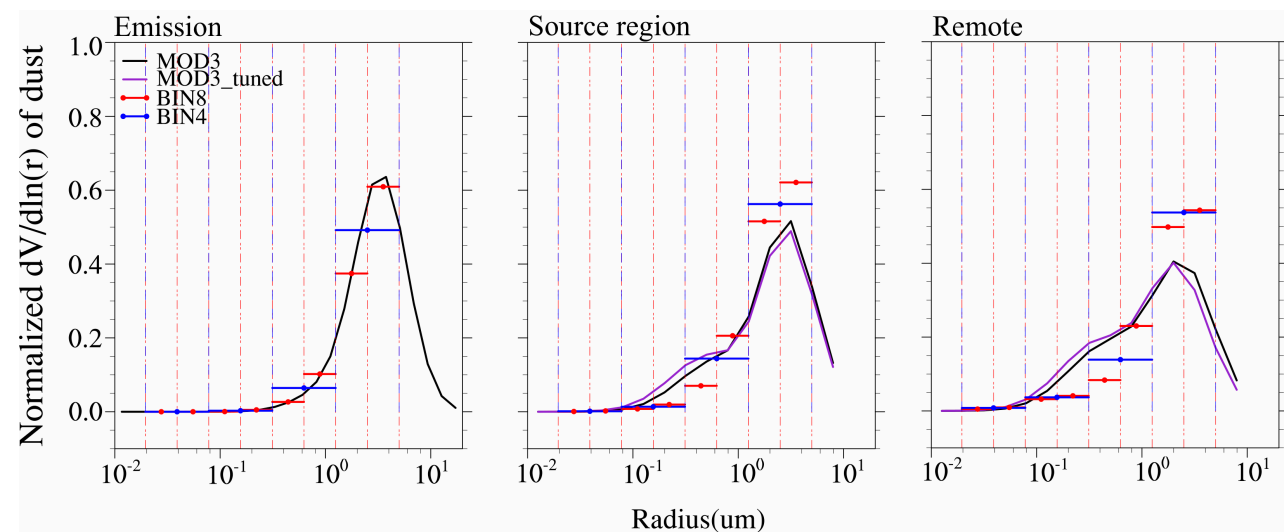

Fig. 6. Normalized size distribution of dust at emission over source regions and over remote regions in 2011 from the WRF-Chem simulations in the cases BIN8, BIN4, MOD3, and MOD3_tuned. Over source and remote regions, only dust above $1 \mathrm{~km}$ is sampled for the size distribution to avoid the impact of sea salt emission over remote regions.

The ratios of $\mathrm{PM}_{2.5}$-Dust $/ \mathrm{PM}_{10}$-Dust between MOD3 and MOD3_tuned are similar.

\subsubsection{Dust dry and wet deposition}

The BIN8, BIN4, and MOD3 cases simulate different dry and wet deposition fluxes due to their different dust mass loading and size distributions resulting from the different size representations, although the same parameterizations for the fundamental processes of dust dry and wet deposition are used. Figure 8 shows the spatial distributions of dust dry, wet, and total deposition fluxes in 2011 from the WRFChem simulations in the BIN8 case and the difference in the BIN4, MOD3, and MOD3_tuned cases from the BIN8 case. It should be noted here that the dust dry and wet deposition fluxes shown are for dust particles smaller than $10 \mu \mathrm{m}$ in diameter in the BIN8 and BIN4 cases but for all-size dust particles in the MOD3 and MOD3_tuned cases. The fluxes for particles with $D<10 \mu \mathrm{m}$ in the cases of MOD3 and MOD3_tuned cannot be obtained, since the model only simulates the integrated total fluxes instead of the size-resolved fluxes for dry and wet removal. However, the mass loading of $\mathrm{PM}_{10}$-Dust is only $\sim 5 \%$ less than that of all-size dust (Table 1). The dry deposition flux simulated by the BIN8 case shows larger spatial variability. It reaches $\sim 200 \mathrm{~g} \mathrm{~m}^{-2}$ over the desert regions due to the highest dust mass loading there, and decreases significantly to merely $\sim 0.1 \mathrm{~g} \mathrm{~m}^{-2}$ over the remote oceans. Dust dry deposition fluxes are mainly determined by the dust mass loading, while its wet deposition fluxes are determined by both mass loading and precipitation. Therefore, the spatial variability of wet deposition fluxes is less heterogeneous than that of dry deposition fluxes, because precipitation is low over the desert regions where the dust mass loading is high. The dust wet deposition flux reaches $50 \mathrm{~g} \mathrm{~m}^{-2}$ over the continents near the deserts and $1 \mathrm{~g} \mathrm{~m}^{-2}$ over the oceans. In general, the dust dry deposition fluxes are larger over the continent but smaller over the ocean than the dust wet deposition fluxes. As a domain average, BIN8 simulates dust dry deposition fluxes of $3120 \mathrm{Tg} \mathrm{yr}^{-1}$, which is more than a factor of 2 of the dust wet deposition fluxes $\left(1365 \mathrm{Tg} \mathrm{yr}^{-1}\right)$.

In general, BIN4 simulates smaller dust dry deposition fluxes over the desert regions but larger values over the remote regions, and $3 \%$ lower on a domain average $\left(3043 \mathrm{Tg} \mathrm{yr}^{-1}\right.$ ) than BIN8. The dust wet deposition flux (1460 $\mathrm{Tg} \mathrm{yr}^{-1}$ on a domain average) is larger $(6 \%$ on a domain average) in the BIN4 case than that in the BIN8 case globally. The difference in simulating dust dry deposition fluxes between MOD3 and BIN8 is much larger than that between BIN4 and BIN8. MOD3 simulates larger dust dry deposition fluxes than BIN8 globally. The difference in simulating dust wet deposition between MOD3 and BIN8 is more heterogeneous in terms of spatial distribution near the desert regions with positive and negative values. The difference in dust total deposition fluxes between MOD3 and BIN8 is dominated by their difference in dust dry deposition fluxes. MOD3_tuned simulates much smaller dust dry and wet deposition fluxes than BIN8 globally, mainly due to its much lower dust mass loading. The atmospheric mass balance of dust is summarized in Table 1. Since the simulations are conducted with boundaries in meridional direction, there is also a dust mass balance term for transport. It is noteworthy that the contributions of transport in all four cases are negligible ( $<1 \%$ of the dust emission and deposition terms).

\subsubsection{Dust lifetime}

Since the dust dry and wet deposition fluxes are proportional to its mass loading, the removal rate of dust can be better demonstrated in dust atmospheric lifetime. Figure 9 shows the spatial distribution of dust atmospheric lifetime against the total removal (dry and wet deposition) in 2011 from the WRF-Chem simulations in the BIN8 case; and the difference in the cases of BIN4, MOD3, and MOD3_tuned from BIN8. 

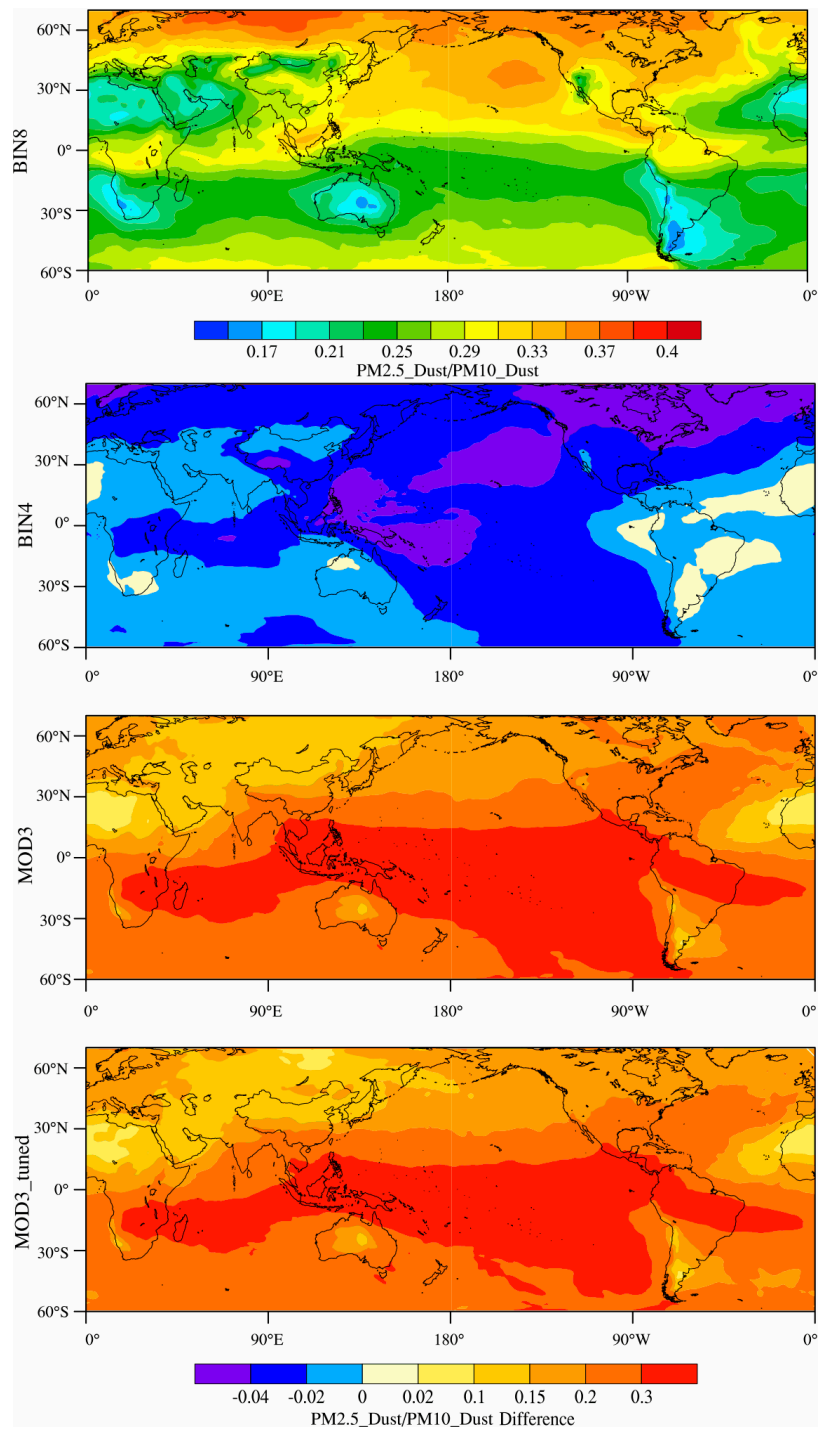

Fig. 7. Spatial distribution of $\mathrm{PM}_{2.5}$-Dust to $\mathrm{PM}_{10}$-Dust mass ratio from the WRF-Chem simulations in the BIN8 case in 2011; and the difference in the cases BIN4, MOD3, and MOD3_tuned from BIN8.

The dust lifetime against the total removal is calculated by dividing the dust mass loading $\left(\mu \mathrm{g} \mathrm{m}^{-2}\right)$ by the dust total deposition fluxes $\left(\mu \mathrm{g} \mathrm{m}^{-2} \mathrm{day}^{-1}\right)$ at each grid. In the BIN8 case, the dust lifetime is relatively short (as low as 1 day) near the desert regions and increases significantly to 10 days (up to 25 days) over the remote oceans such as the northeastern Pacific. The short dust lifetime over the desert regions is due to the high removal rate of large dust particles emitted there. The domain-averaged dust lifetime is $\sim 3.2$ days in BIN8. Although there is a difference between BIN4 and BIN8 in simulating dust total deposition fluxes, the lifetime of dust in BIN4 is close to that in BIN8 globally with a difference smaller than 1 day. BIN4 simulates a similar domainaveraged dust lifetime of $\sim 3.3$ days as BIN8. In general,
MOD3 simulates longer dust lifetime globally because it retains more fine particles than BIN8. The difference between MOD3 and BIN8 in dust lifetime near the dust source regions is smaller than 1 day, while their difference increases to 3 days (up to 10 days) over the remote regions. It is noteworthy that the domain-averaged dust lifetime is $\sim 3.5$ days in MOD3, only $10 \%$ higher than that in BIN8. This suggests that the global dust lifetime is mainly determined by the dust lifetime near the dust source regions. MOD3_tuned simulates a very similar dust lifetime as MOD3 due to their similar dust size distributions.

\subsubsection{Dust number loading}

Besides dust mass loading and AOD, dust number concentration is also a critical factor in simulating dust climatic impact. Dust number concentration is often used in parameterizations of IN number concentrations (e.g., Liu and Penner, 2005; Phillips et al., 2008; DeMott et al., 2010) and hence determines how dust influences clouds and precipitation. The different dust size distributions in the four cases also result in significantly different dust number concentrations. Figure 10 shows the spatial distribution of dust number loading in 2011 from the WRF-Chem simulation in the BIN8 case, and the difference in the cases of BIN4, MOD3, and MOD3_tuned from the BIN8 case. In the BIN8 case, the spatial distribution of dust number loading follows closely that of dust mass loading (Fig. 4) with the highest number loading over the desert regions. However, the spatial gradient of dust number loading is smaller than that of dust mass loading due to the faster removal rate of mass than that of number in general.

Although the dust mass loading errors in the BIN4, MOD3, and MOD3_tuned cases against BIN8 are quite diverse spatially, all three cases overestimate the dust number loading compared to BIN8. The maximum overestimation occurs over the desert regions. BIN4 generally simulates up to $50 \%$ more dust number loading over most regions except the southern oceans where the relative difference can reach $100 \%$ but the dust number loading is quite low. The difference in MOD3 and MOD3_tuned from BIN8 is tremendous. The dust number loading is 10 times larger over the desert regions and up to more than 100 times larger over the remote regions in MOD3 and MOD3_tuned than BIN8. There is no doubt that this large difference in dust number loading will significantly affect the ice cloud formation as previous studies considered dust as an efficient aerosol species for IN in the model. The impact of size representation on dust IN effect and hence dust indirect radiative effect deserves more detailed studies in the future.

\subsection{Impact of size representation on dust radiative forcing}

The difference in dust mass and number loading among the cases of BIN8, BIN4, MOD3, and MOD3_tuned results in 

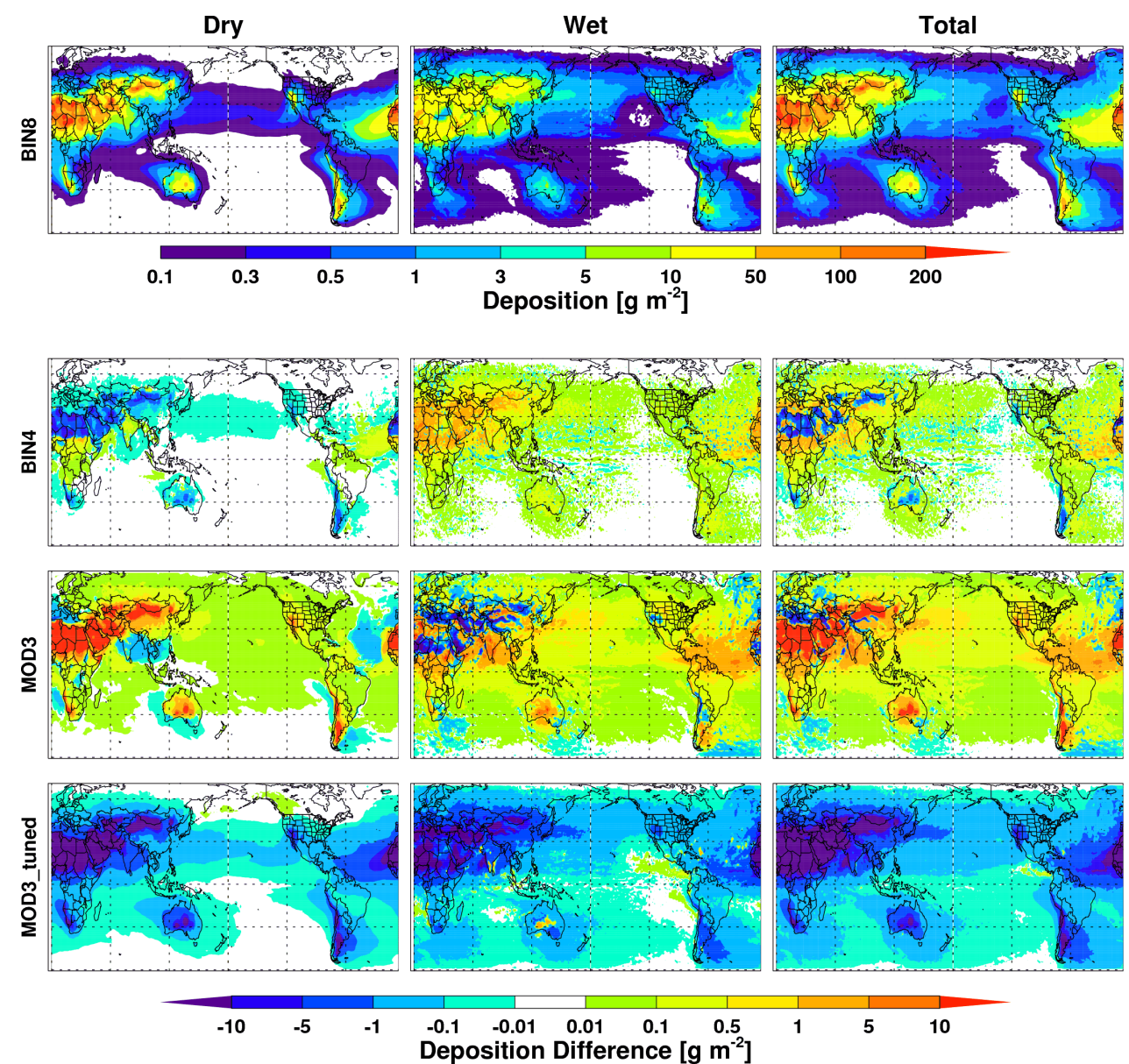

Deposition Difference $\left[\mathrm{g} \mathrm{m}^{-2}\right]$

Fig. 8. Spatial distributions of dust deposition fluxes due to dry removal, wet removal, and their sum from the WRF-Chem simulations in the BIN8 case; and difference in cases BIN4, MOD3, and MOD3_tuned from BIN8, in 2011.

different dust radiative forcing. Figure 11 shows the spatial distribution of dust radiative forcing at the top of atmosphere (TOA), in the atmosphere, and at the surface in 2011 from the WRF-Chem simulations in the cases of BIN8, BIN4, MOD3, and MOD3_tuned. The domain-averaged dust radiative forcing is summarized in Table 2. The spatial distributions of dust radiative forcing follow closely the dust mass loading in the four cases. At the surface, dust reduces net radiative fluxes and results in cooling effect in all the four cases. The MOD3 and MOD3_tuned cases simulate larger dust surface radiative forcing than BIN8 and BIN4 due to their higher dust mass loading and AOD. It is interesting to note that BIN4 simulates comparable dust mass loading and smaller dust AOD at $550 \mathrm{~nm}$ but $\sim 20 \%$ larger dust surface cooling effect compared to BIN8. Further analysis shows that BIN4 simulates higher dust AOD at wavelengths shorter than $550 \mathrm{~nm}$ (such as $300 \mathrm{~nm}$ and $400 \mathrm{~nm}$ ) than BIN8, which results in larger (more negative) dust surface radiative forcing. The difference in dust AOD at different wavelengths between BIN8 and BIN4 likely results from their different dust size distributions.
In the atmosphere, dust leads to a warming effect. It is surprising that BIN4 and MOD3_tuned simulate the highest and smallest dust warming effect, respectively, among the four cases. This is different from the comparison in dust AOD among the four cases (Fig. 3 and Table 1), which shows the largest and smallest dust AOD for MOD3 and BIN4, respectively. Figure 12 shows the longitude-height cross section of dust-induced radiative heating rate in 2011 from the WRF-Chem simulations in the cases of BIN8, BIN4, MOD3, and MOD3_tuned. Dust heats the atmosphere from the surface up to $12 \mathrm{~km}$. The pattern of dust-induced radiative heating profile follows the distribution of dust mass concentration as shown in Fig. 5 in each case centering at the regions within $\pm 30^{\circ} \mathrm{E}$. It shows consistent results that BIN4 simulates the largest dust-induced radiative heating through the atmosphere up to $12 \mathrm{~km}$ among the four cases. The maximum dust-induced heating rate reaches $0.04 \mathrm{~K} \mathrm{day}^{-1}$ below $4 \mathrm{~km}$ in the BIN4 case.

To explore the reason why the dust heating rate does not monotonically vary with the dust AOD among the four cases, the dust absorptivity should be examined, which can 

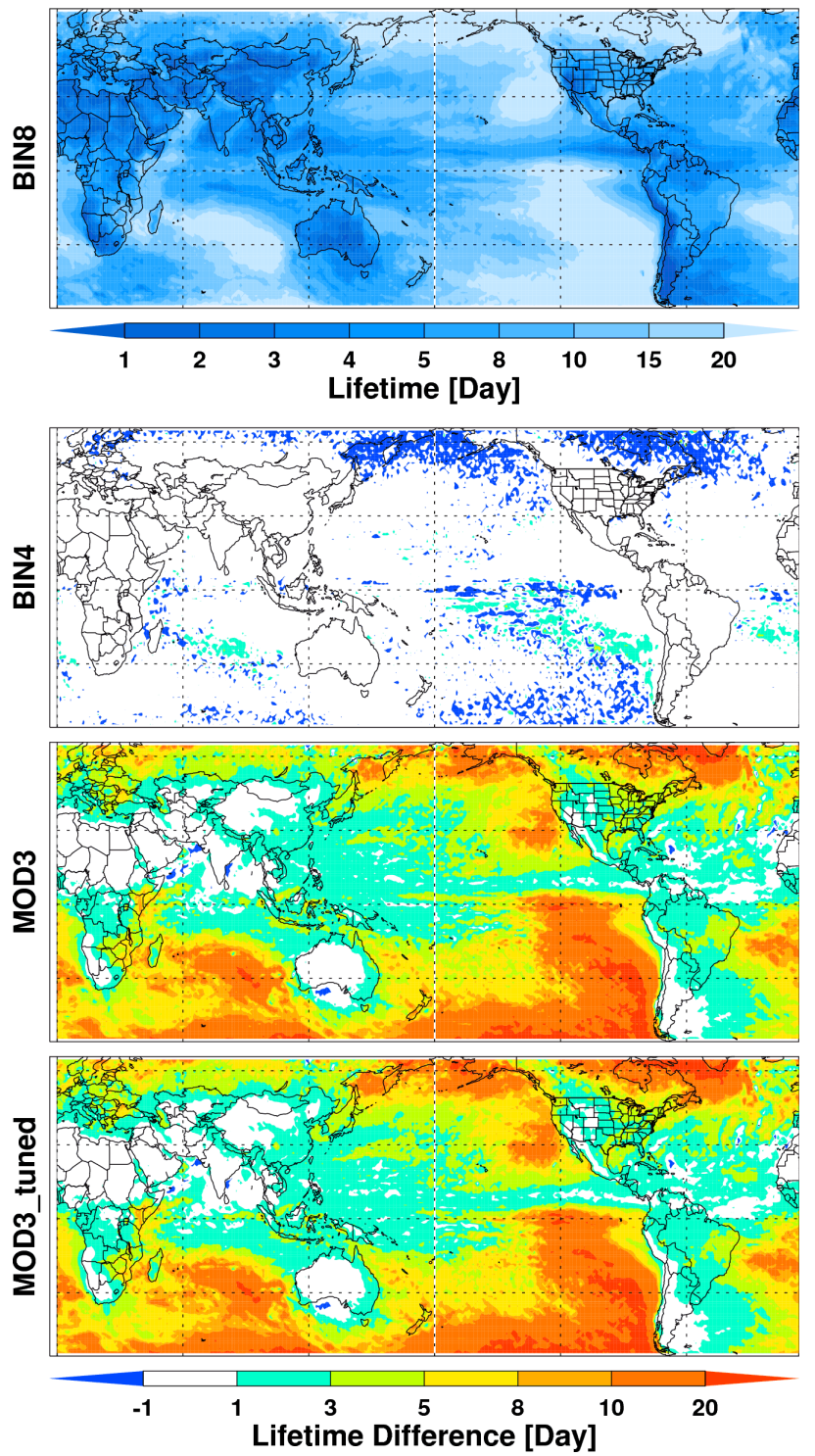

Fig. 9. Spatial distribution of dust atmospheric lifetime against total removal (dry + wet) in 2011 from the WRF-Chem simulations in the case of BIN8; and the difference in the cases of BIN4, MOD3, and MOD3_tuned from BIN8.

Table 2. Radiative forcing of dust in WRF-Chem experiments. The values in parenthesis are radiative forcing efficiency (i.e., radiative forcing per unit AOD).

\begin{tabular}{lcccc}
\hline & BIN8 & BIN4 & MOD3 & MOD3_tuned \\
\hline TOA & $-0.56(-14)$ & $-0.24(-8)$ & $-2.20(-23)$ & $-1.31(-25)$ \\
ATM & $0.46(12)$ & $0.96(32)$ & $0.66(7)$ & $0.39(7)$ \\
BOT & $-1.02(-26)$ & $-1.20(-40)$ & $-2.87(-31)$ & $-1.70(-32)$ \\
\hline
\end{tabular}

be reflected in the dust single scattering albedo (SSA). Figure 13 shows the vertical profiles of global mean dust SSA at $550 \mathrm{~nm}$ in 2011 from the WRF-Chem simulations in the cases of BIN8, BIN4, MOD3, and MOD3_tuned. It clearly
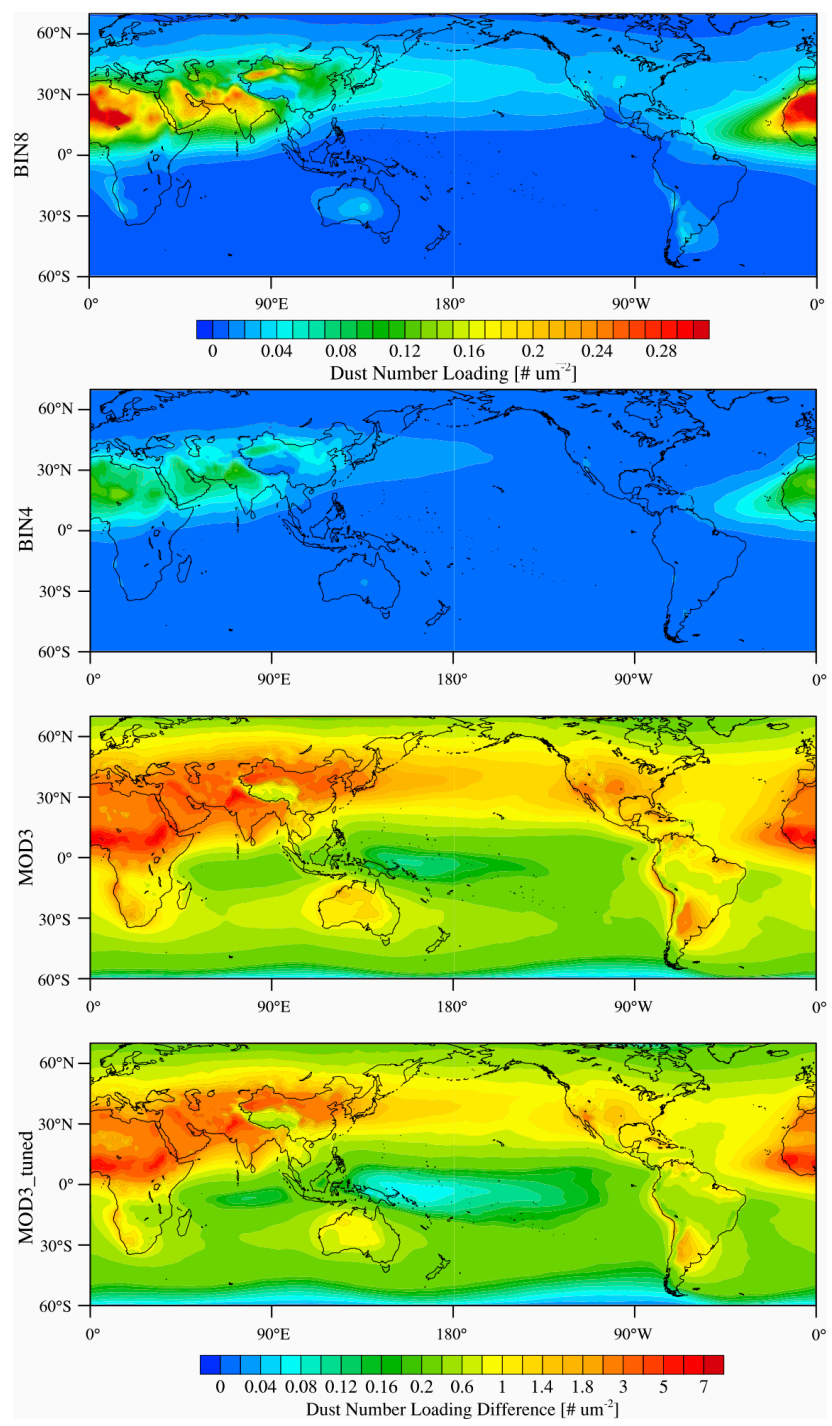

Fig. 10. Spatial distribution of dust number loading in 2011 from the WRF-Chem simulation in the BIN8 case, and the difference in the cases of BIN4, MOD3, and MOD3_tuned from the BIN8 case.

demonstrates that BIN4 simulates the smallest dust SSA $(\sim 0.90$ below $4 \mathrm{~km})$ indicating the strongest dust absorption among the four cases. BIN8 simulates a larger value of dust SSA $(\sim 0.93$ below $4 \mathrm{~km})$ indicating weaker dust absorption. MOD3 and MOD3_tuned simulate very similar and the largest dust SSA of 0.96 below $4 \mathrm{~km}$ indicating the weakest dust absorption. In this study, dust optical property (i.e., refractive index) is set the same for all four cases. Therefore, the main factor determining dust absorption is its size distribution (Tegen and Lacis, 1996). MOD3 and MOD3_tuned simulate similar dust absorptivity due to their similar dust size distributions (Fig. 6). They also simulate the weakest dust absorptivity due to their largest fractions of fine particles. BIN4 with coarser resolution for the dust size distribution simulates stronger dust absorptivity than BIN8. 

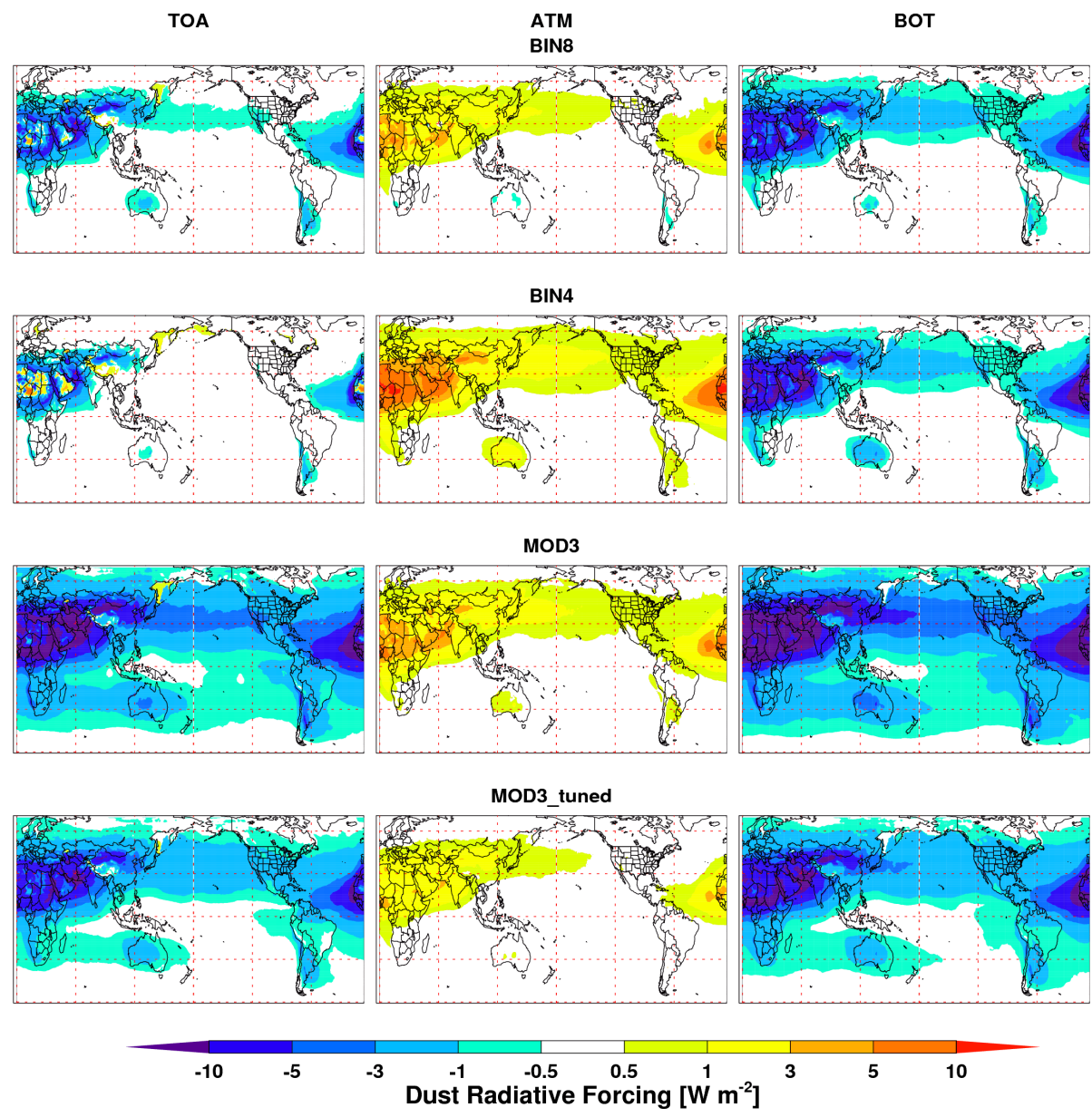

Fig. 11. Spatial distribution of dust radiative forcing at the TOA, in the atmosphere, and at the surface in 2011 from the WRF-Chem simulations in the cases of BIN8, BIN4, MOD3, and MOD3_tuned.

MOD3_tuned with the smallest dust AOD and the weakest dust absorptivity simulates the smallest dust radiative heating rate. BIN4 with smaller dust AOD but stronger dust absorptivity simulates larger dust radiative heating rate than MOD3 and MOD3_tuned.

At the TOA, dust results in a cooling effect in all four cases. The spatial distribution of dust TOA radiative forcing also follows closely the dust mass loading and AOD in each case. BIN4 simulates the weakest dust TOA cooling effect due to its strongest absorbing effect in the atmosphere. MOD3 simulates the strongest dust TOA cooling effect due to its largest dust AOD. Overall, with the same amount and size distribution of emitted dust, the different size representations in the four cases could result in a significant difference of a factor of $2 \sim 3$ in dust surface cooling effect $\left(-1.02 \sim-2.87 \mathrm{~W} \mathrm{~m}^{-2}\right)$ and atmospheric warming effect $\left(0.39 \sim 0.96 \mathrm{~W} \mathrm{~m}^{-2}\right)$ and in a tremendous difference of a factor of $\sim 10$ in dust TOA cooling effect $(-0.24 \sim$ $-2.20 \mathrm{~W} \mathrm{~m}^{-2}$ ).

Furthermore, different size representations also lead to significant differences in dust radiative forcing efficiencies (i.e., radiative forcing per unit AOD), also summarized in Table 2. The radiative forcing efficiency can be used as an indication of the impact of size distributions on radiative forcing. With similar dust size distributions (Fig. 6), the MOD3 and MOD3_tuned cases simulate a similar dust radiative forcing efficiency regardless of their large difference in AOD. The two mode cases simulate the largest dust radiative forcing efficiency at TOA and the BIN4 case simulates the smallest value. The BIN8 case is in between. Although the mode size representation simulates larger dust radiative forcing at the surface than the bin size representation, the BIN4 case simulates the largest dust radiative forcing efficiency at the surface and in the atmosphere. The BIN8 case and the two mode cases simulate the smallest dust radiative forcing efficiency at the surface and in the atmosphere, respectively. Overall, the difference among the four cases in dust radiative forcing efficiency is a factor of 3 at TOA, a factor of 4.5 in the atmosphere, and a factor of 1.5 at the surface, which is smaller than the difference in dust radiative forcing. 

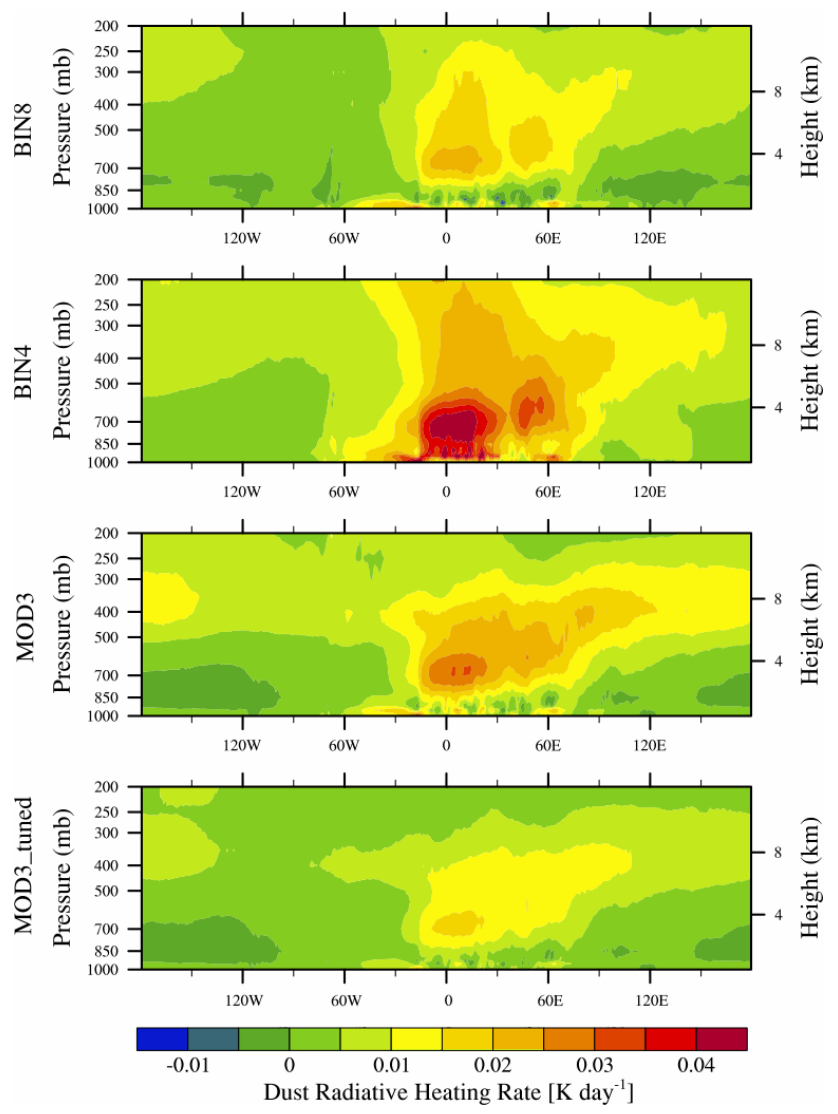

Fig. 12. Cross section of dust-induced radiative heating rate in 2011 from the WRF-Chem simulations in the cases of BIN8, BIN4, MOD3, and MOD3_tuned.

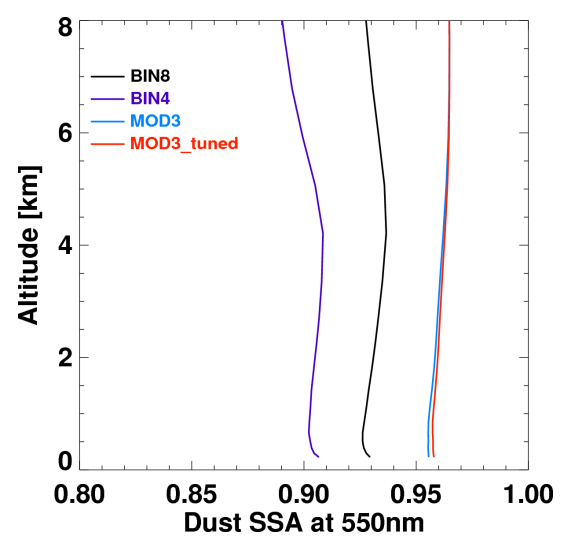

Fig. 13. Profiles of global mean dust SSA at $550 \mathrm{~nm}$ in 2011 from the WRF-Chem simulations in the cases of BIN8, BIN4, MOD3, and MOD3_tuned.

\section{Summary and conclusion}

Using the framework of WRF-Chem with three different aerosol size representations (i.e., MOD3 with 3-mode, BIN4 with 4-bin, and BIN8 with 8-bin), but the same parameteri- zations for the fundamental processes of dust emission and removal, this study examines the uncertainties rooting from size representations in simulating dust mass balance and radiative forcing quasi-globally $\left(180^{\circ} \mathrm{W}-180^{\circ} \mathrm{E}\right.$ and $60^{\circ} \mathrm{S}-$ $70^{\circ} \mathrm{N}$ ). The WRF-Chem simulation in the BIN8 case is taken as a benchmark for error analysis, since the 8-bin approach can better resolve the dust size distribution (Zhao et al., 2010). The difference between the results from the BIN 8 case and the BIN4 or MOD3 cases are analyzed as the errors in 3mode or 4-bin size representations that are widely used in global climate models due to their computational efficiency. One additional case (MOD3_tuned with 3-mode) is also conducted with half of the total dust emission of the former three cases to identify the error in a 3-mode size representation when AOD observations are used to constrain dust emission over the dust source region.

The cases of BIN8, BIN4, MOD3, and MOD3_tuned simulate different size distributions of dust in the atmosphere. The biases of the 4-bin (BIN4) and 3-mode (MOD3 and MOD3_tuned) approaches against the 8-bin approach (BIN8) in simulating dust size distributions result from their relatively inaccurate size representations. The size distribution with the 4-bin approach (BIN4) follows that of the 8-bin approach (BIN8) but has coarser size resolution. This results in fewer fine dust particles in the 4-bin approach than the 8bin approach, as reflected by the difference in the ratios of $\mathrm{PM}_{2.5}$-Dust / $\mathrm{PM}_{10}$-Dust between these two approaches. The 3-mode approach (MOD3 and MOD3_tuned) retains more fine dust particles but fewer coarse dust particles compared to the 8-bin approach. The prescribed $\sigma_{g}$ (i.e., with a constant value) is the main contributor to the bias of the 3-mode approach in representing dust size distribution (Zhao et al., 2010). This result is consistent with Mann et al. (2012), who found that the modal approach simulates lower number concentrations for larger aerosol particles than the bin approach. In addition, they also found that the result from the modal approach is sensitive to the fixed $\sigma_{g}$. The difference in dust size distributions significantly impacts the dust lifetime among the four cases. BIN8 simulates a domain-averaged dust lifetime of $\sim 3.2$ days with a shorter lifetime $(\sim 1$ day) near the dust source regions and a longer lifetime ( $>10$ days) over the remote oceans. The dust lifetime in BIN4 is less than 1 day longer than BIN8 globally. The MOD3 and MOD3_tuned cases simulate relatively small differences in dust lifetime ( $\sim 1$ day longer) relative to BIN8 near the dust source regions, but the difference increases significantly to 3 days (up to 10 days) longer lifetime over the remote regions. However, it is noteworthy that the difference in domain-averaged dust lifetime is relatively small among the four cases, i.e., $\sim 3.2$ days in BIN8 and BIN4 and $\sim 3.5$ days in MOD3 and MOD3_tuned, indicating that the global dust lifetime is mainly determined by the dust lifetime near dust source regions.

With the same emission but different size representations and thus different size distributions and lifetimes of dust 
in the atmosphere, BIN8 simulates a dust mass loading of $39 \mathrm{Tg}$, while BIN4 and MOD3 simulate $3 \%(40.2 \mathrm{Tg}$ ) and $25 \%(49.1 \mathrm{Tg})$ higher dust mass loading, respectively, indicating an uncertainty of dust mass loading of up to $25 \%$ due to the three size representations. Over the dust source regions, although the absolute difference between BIN8 and BIN4 or MOD3 is large, the relative errors in BIN4 and MOD3 compared to BIN8 are within $+10 \%$. The relative errors increase with height and the distance downwind of dust source regions and reach $100 \%$ in MOD3 over the remote regions up to $4 \mathrm{~km}$ above the surface. On the contrary, the relative error in MOD3_tuned against BIN8 is large (up to 50\% negative bias) over the dust source region and decreases to $<10 \%$ negative bias or even positive bias over the remote regions. The different dust mass loading and size distributions among the four cases also result in significantly different dry and wet deposition fluxes and dust number concentrations. The dust number loading simulated by the 4-bin (BIN4) and 3-mode approaches (MOD3 and MOD3_tuned) are up to a factor of 2 and 100 of BIN8, respectively.

The difference in dust AOD among the three cases is up to a factor of 3, much larger than their difference in dust mass loading. It is noteworthy that BIN4 simulates $3 \%$ higher dust mass loading but $25 \%$ lower dust AOD than BIN8. With half the dust emission, MOD3_tuned simulates 30\% lower dust mass loading but $35 \%$ higher dust AOD than BIN8. The difference in dust AOD results in different dust radiative forcing among the four cases. The dust-induced surface cooling and atmospheric warming have a difference of about a factor of 3 among the four cases. The difference in dustinduced atmospheric warming among the four cases results from their difference in dust AOD and dust absorptivity. The 4-bin approach (BIN4) with coarser size resolution simulates stronger dust absorptivity than the 8-bin approach (BIN8), while the 3-mode approach (MOD3 and MOD3_tuned) simulates weaker dust absorptivity. At the TOA, dust results in cooling effect in all the four cases with an uncertainty of a factor of 10. The radiative forcing efficiency is also analyzed to reflect the impact of size distributions on radiative forcing. With the similar dust size distributions, the two mode cases simulate similar dust radiative forcing efficiencies regardless of their large difference in AOD. It is noteworthy that the difference resulted from the size representations in dust radiative forcing efficiency is smaller than that in dust radiative forcing.

In this study, the total global dust emission (for dust particles with diameter $<10 \mu \mathrm{m}$ ) estimated based on the top-down method (i.e., using satellite retrievals to constrain model simulated dust AOD over the source regions, which is commonly used by the modeling community) with the 8-bin size representation is $4600 \mathrm{Tg} \mathrm{yr}^{-1}$. This value is near the higher end of the range reported by Huneeus et al. (2011). However, the estimate of total dust emission can be reduced by $50 \%$ to $2400 \mathrm{Tg} \mathrm{yr}^{-1}$ if the top-down method is applied using a model with 3-mode size representation. This indicates an un- certainty of a factor of 2 in dust emission derived by the topdown method solely due to the size representations in models (3-mode versus 8-bin here). Comparison between BIN4 with BIN8 indicates that models with four dust size bins may simulate dust mass loading and AOD reasonably well but have positive bias in both dust number loading and absorptivity. A sub-bin size distribution is needed to appropriately calculate dust optical properties and number concentration using 4-size bin representation. The 3-mode representation has biases in mass, number, and optical properties. Models with three dust size modes have relatively large biases in simulating dust mass loading and radiative forcing, even with constrained AOD by observations. A three-moment aerosol size parameterization (i.e., predicting aerosol mass, number, and surface area and thus $\sigma_{g}$ ) may be needed for the mode approach to appropriately represent dust size distributions in the atmosphere (Binkowski and Roselle, 2003). This study found a difference of $25 \%$ in dust mass loading between the simulations using modal and sectional size representations, which is consistent with what Mann et al. (2012) found for other aerosols. However, the difference in dust radiative forcing (up to a factor of 10) is much larger, indicating aerosol size representation may have much larger impact on modeling aerosol radiative forcing than aerosol mass.

In order to better capture the realistic meteorology and also minimize the feedback of dust impact on meteorology, the simulated winds are nudged towards the reanalysis data so that our analysis can focus on the impact of size representations on dust mass loading and radiative forcing in this study. However, uncertainties in simulating dust impact on climate and oceanic ecosystems due to size representations need to be quantified, because of the significant difference in dust direct radiative forcing, dust number loading (implying dust indirect radiative effect), and dust deposition fluxes among the simulations with different size representations. This study with quasi-global configuration also cannot assess the size impact on dust radiative effect over the polar regions, which may be of interest due to the potential role of dust in polar amplification of global warming (Lambert et al., 2013). In addition, the impact of size representation on the long-range transport of dust may also be worthy of further investigation due to the recently raised concern about the impact of longrange transported dust (e.g., Asian dust and Saharan dust) on the air quality and regional hydrological cycle of the western US (Yu et al., 2012; Creamean et al., 2013). The uncertainties identified in this study depend to some degree on the size distribution of emitted dust and the $\sigma_{g}$. The results may also be somewhat sensitive to how processes such as dry and wet deposition are parameterized in the model. To fully explore the uncertainties in dust mass balance and radiative forcing simulated by different models, a systematic comparison of multiple sources of uncertainties and their interactions in a multi-model framework would be beneficial. 
Acknowledgements. This research was supported by the Office of Science of the US Department of Energy (DOE) as part of the Regional \& Global Climate Modeling (RGCM) program. This study used computing resources from the National Energy Research Scientific Computing Center, which is supported by the US Department of Energy Office of Science under Contract No. DEAC02-05CH11231 and the PNNL Institutional Computing. Pacific Northwest National Laboratory is operated by Battelle Memorial Institute for the DOE under contract DE-AC05-76RL01830. Jasper Kok was partly supported by the National Science Foundation under Award AGS 1137716. We thank Nicole Riemer for the editorial help. Insightful comments offered by the two anonymous referees are highly appreciated. The authors thank Jiwen Fan for providing an internal review.

Edited by: N. Riemer

\section{References}

Ackermann, I. J., Hass, H., Memmesheimer, M., Ebel, A., Binkowski, F. S., and Shankar, U.: Modal aerosol dynamics model for Europe: Development and first applications, Atmos. Environ., 32, 2981-2999, 1998.

Balkanski, Y., Schulz, M., Claquin, T., and Guibert, S.: Reevaluation of Mineral aerosol radiative forcings suggests a better agreement with satellite and AERONET data, Atmos. Chem. Phys., 7, 81-95, doi:10.5194/acp-7-81-2007, 2007.

Barnard, J. C., Fast, J. D., Paredes-Miranda, G., Arnott, W. P., and Laskin, A.: Technical Note: Evaluation of the WRF-Chem "Aerosol Chemical to Aerosol Optical Properties" Module using data from the MILAGRO campaign, Atmos. Chem. Phys., 10, 7325-7340, doi:10.5194/acp-10-7325-2010, 2010.

Bey, I., Jacob, D. J., Yantosca, R. M., Logan, J. A., Field, B. D., Fiore, A. M., Li, Q., Liu, H., Mickley, L. J., and Schultz, M. G.: Global modeling of tropospheric chemistry with assimilated meteorology: Model description and evaluation, J. Geophys. Res., 106, 23073-23096, 2001.

Bian, H. S. and Zender, C. S.: Mineral dust and global tro- pospheric chemistry: Relative roles of photolysis and hetero- geneous uptake, J. Geophys. Res.-Atmos., 108, 4672, doi:10.1029/2002JD003143, 2003.

Binkowski, F. S. and Shankar, U.: The Regional Particulate Matter Model: 1. Model Description and Preliminary Results, J. Geophys. Res., 100, 26191-26209, 1995.

Binkowski, F. S. and Shankar, U.: Models-3 Community Multiscale Air Quality (CMAQ) model aerosol component: 1. Model description, J. Geophys. Res., 108, 4183, doi:10.1029/2001JD001409, 2003.

Chadwick, O. A., Derry, L. A., Vitousek, P. M., Huebert, B. J., and Hedin, L. O.: Changing sources of nutrients during four million years of ecosystem development, Nature, 397, 491-497, doi:10.1038/17276, 1999.

Chen, S., Huang, J., Zhao C.,, Qian, Y., Leung, L. R., and Yang, B.: Modeling the Transport and Radiative Forcing of Taklimakan Dust over the Tibetan Plateau in Summer, J. Geophys. Res., 118, 797-812, doi:10.1002/jgrd.50122, 2013.

Chen, Y. S., Sheen, P. C., Chen, E. R., Liu, Y. K., Wu, T. N., and Yang, C. Y.: Effects of Asian dust storm events on daily mortality in Taipei, Taiwan, Environ. Res., 95, 151-155, doi:10.1016/j.envres.2003.08.008, 2004.

Chapman, E. G., Gustafson Jr., W. I., Easter, R. C., Barnard, J. C., Ghan, S. J., Pekour, M. S., and Fast, J. D.: Coupling aerosolcloud-radiative processes in the WRF-Chem model: Investigating the radiative impact of elevated point sources, Atmos. Chem. Phys., 9, 945-964, doi:10.5194/acp-9-945-2009, 2009.

Creamean, J. M., Suski, K. J., Rosenfeld, D., Cazorla, A., DeMott, P. J., Sullivan, R. C., White, A. B., Ralph, F. M., Minnis, P., Comstock, J. M., Tomlinson, J. M., and Prather, K. A.: Dust and Biological Aerosols from the Sahara and Asia Influence Precipitation in the Western U.S., Science, 339, 1572-1578, doi:10.1126/science.1227279, 2013.

Darmenova, K., Sokolik, I. N., Shao, Y., Marticorena, B., and Bergametti, G.: Development of a physically based dust emission module within the Weather Research and Forecasting (WRF) model: Assessment of dust emission parameterizations and input parameters for source regions in Central and East Asia, J. Geophys. Res., 114, D14201, doi:10.1029/2008JD011236, 2009.

DeMott, P. J., Prenni, A., Liu, X., Kreidenweis, S. M., Petters, M. D., Twohy, C. H., Richardson, M. S., Eidhammer, T., and Rogers, D. C.: Predicting global atmospheric ice nuclei distributions and their impacts on climate, Proc. Natl. Acad. Sci. USA, 107, 11217-11222, doi:10.1073/pnas.0910818107, 2010.

Dentener, F., Kinne, S., Bond, T., Boucher, O., Cofala, J., Generoso, S., Ginoux, P., Gong, S., Hoelzemann, J. J., Ito, A., Marelli, L., Penner, J. E., Putaud, J.-P., Textor, C., Schulz, M., van der Werf, G. R., and Wilson, J.: Emissions of primary aerosol and precursor gases in the years 2000 and 1750 prescribed data-sets for AeroCom, Atmos. Chem. Phys., 6, 4321-4344, doi:10.5194/acp-64321-2006, 2006.

Diner, D. J., Beckert, J., Reilly, T., Bruegge, C., Conel, J., Kahn, R., Martonchik, J., Ackerman, T., Davies, R., Gerstl, S., Gordon, H., Muller, J., Myneni, R., Sellers, P.J., Pinty, B., and Verstraete, M.: Multi-angle Imaging SpectroRadiometer (MISR) instrument description and experiment overview, IEEE T., Geosci. Remote, 36, 1072-1087, 1998.

Diner, D. J., Abdou, W. A., Bruegge, C. J., Conel, J. E., Crean, K. A., Gaitley, B. J., Helmlinger, M. C., Kahn, R. A., Martonchik, J. V., and Pilorz, S. H.: MISR aerosol optical depth retrievals over southern Africa during the SAFARI-2000 dry season campaign, Geophys. Res. Lett., 28, 3127-3130, 2001.

Easter, R. C., Ghan, S. J., Zhang, Y., Saylor, R. D., Chapman, E. G., Laulainen, N. S., Abdul-Razzak, H., Leung, L. R., Bian, X., and Zaveri, R. A.: MIRAGE: Model Description and Evaluation of Aerosols and Trace Gases. J. Geophys. Res., 109, D20210, doi:10.1029/2004JD004571, 2004.

Fast, J. D, Gustafson Jr., W. I., Easter, R. C., Zaveri, R. A., Barnard, J. C., Chapman, E. G., and. Grell, G. A.: Evolution of ozone, particulates, and aerosol direct forcing in an urban area using a new fully-coupled meteorology, chemistry, and aerosol model, J. Geophys. Res., 111, D21305, doi:10.1029/2005JD006721, 2006.

Forster, P., Ramaswamy, V., Artaxo, P., Berntsen, T., Betts, R., Fahey, D. W., Haywood, J., Lean, J., Lowe, D. C., Myhre, G., Nganga, J., Prinn, R., Raga, G., Schulz, M., and Van Dorland, R.: Radiative Forcing of Climate Change, in Climate Change 2007: The Physical Science Basis. Contribution of Working Group I to the Fourth Assessment Report of the Intergovernmental Panel on Climate Change, edited by: Solomon, S., Qin, D., Manning, M., 
Chen, Z., Marquis, M., Averyt, K. B., Tignor, M., and Miller, H. L., 129-234, Cambridge Univ. Press, Cambridge, UK and New York, NY, USA, 2007.

Ginoux, P., Chin, M., Tegen, I., Prospero, J. M., Holben, B., Dubovik, O., and Lin, S.: Sources and distributions of dust aerosols simulated with the GOCART model, J. Geophys. Res., 106, 20225-20273, 2001.

Gläser, G., Kerkweg, A., and Wernli, H.: The Mineral Dust Cycle in EMAC 2.40: sensitivity to the spectral resolution and the dust emission scheme, Atmos. Chem. Phys., 12, 1611-1627, doi:10.5194/acp-12-1611-2012, 2012.

Gong, S. L.: A parameterization of sea-salt aerosol source function for sub- and super-micron particles, Global Biogeochem. Cy., 17, 1097, doi:10.1029/2003GB002079, 2003.

Grell, G. A., Peckham, S. E., Schmitz, R., and McKeen, S. A., Frost, G., Skamarock, W. C., and Eder, B.: Fully coupled "online" chemistry within the WRF model, Atmos. Environ., 39, 6957-6976, 2005.

Gustafson, W. I., Chapman, E. G., Ghan, S. J., Easter, R. C., and Fast, J. D.: Impact on modeled cloud characteristics due to simplified treatment of uniform cloud condensation nuclei during NEAQS 2004, Geophys. Res. Lett., 34, L19809, doi:10.1029/2007GL030021, 2007.

Herzog, M., Weisenstein, D. K., and Penner, J. E.: A dynamic aerosol module for global chemical transport models: Model description, J. Geophys. Res., 109, D18202, doi:10.1029/2003JD004405, 2004.

Hsu, N. C., Tsay, S., King, M., and Herman, J. R.: Deep blue retrievals of Asian Aerosol Properties during ACEAsia, IEEE Trans. Geosci. Remote Sens., 44, 3180, doi:10.1109/TGRS.2006.879540, 2006

Huang, J., Minnis, P., Yi, Y., Tang, Q., Wang, X., Hu, Y., Liu, Z., Ayers, K., Trepte, C., and Winker, D.: Summer dust aerosols detected from CALIPSO over the Tibetan Plateau, Geophys. Res. Lett., 34, L18805, doi:10.1029/2007GL029938, 2007.

Huneeus, N., Schulz, M., Balkanski, Y., Griesfeller, J., Prospero, J., Kinne, S., Bauer, S., Boucher, O., Chin, M., Dentener, F., Diehl, T., Easter, R., Fillmore, D., Ghan, S., Ginoux, P., Grini, A., Horowitz, L., Koch, D., Krol, M. C., Landing, W., Liu, X., Mahowald, N., Miller, R., Morcrette, J.-J., Myhre, G., Penner, J., Perlwitz, J., Stier, P., Takemura, T., and Zender, C. S.: Global dust model intercomparison in AeroCom phase I, Atmos. Chem. Phys., 11, 7781-7816, doi:10.5194/acp-11-7781-2011, 2011.

Iacono, M. J., Mlawer, E. J., Clough, S. A., and Morcrette, J.-J.: Impact of an improved longwave radiation model, RRTM. on the energy budget and thermodynamic properties of the NCAR community climate mode, CCM3. J. Geophys. Res., 105, 1487314890, 2000.

Jaeglé, L., Quinn, P. K., Bates, T. S., Alexander, B., and Lin, J.-T.: Global distribution of sea salt aerosols: new constraints from in situ and remote sensing observations, Atmos. Chem. Phys., 11, 3137-3157, doi:10.5194/acp-11-3137-2011, 2011.

Kain, J. S.: The Kain-Fritsch Convective Parameterization: An Update, J. Appl. Meteor., 43, 170-181, 2004.

Kain, J. S. and Fritsch, J. M.: A One-Dimensional Entraining/Detraining Plume Model and Its Application in Convective Parameterization, J. Atmos. Sci., 47, 2784-2802, 1990.

Kalenderski, S., Stenchikov, G., and Zhao, C.: Modeling a typical winter-time dust event over the Arabian Peninsula and the Red
Sea, Atmos. Chem. Phys., 13, 1999-2014, doi:10.5194/acp-131999-2013, 2013.

Kaufman, Y. J., Tanré, D., Remer, L. A., Vermote, E. F., Chu, A., and Holben, B. N.: Operational remote sensing of tropospheric aerosol over land from EOS moderate resolution imaging spectroradiometer, J. Geophys. Res., 102, 17051-17067, 1997.

Kim, D., Chin, M., Bian, H., Tan, Q., Brown, M. E., Zheng, T., You, R., Diehl, T., Ginoux, P., and Kucsera, T.: The effect of the dynamic surface bareness on dust source function, emission, and distribution, J. Geophys. Res., 118, 1-16, doi:10.1029/2012JD017907, 2013.

Kim, K. W., Kim, Y. J., and Oh, S. J.: Visibility impairment during Yellow Sand periods in the urban atmosphere of Kwangju, Korea, Atmos. Environ., 35, 5157-5167, 2001.

Kok, J. F.: A scaling theory for the size distribution of emitted dust aerosols suggests climate models underestimate the size of the global dust cycle, Proc. Natl. Acad. Sci., 108, 1016-1021, 2011.

Kokkola, H., Hommel, R., Kazil, J., Niemeier, U., Partanen, A.-I., Feichter, J., and Timmreck, C.: Aerosol microphysics modules in the framework of the ECHAM5 climate model - intercomparison under stratospheric conditions, Geosci. Model Dev., 2, 97-112, doi:10.5194/gmd-2-97-2009, 2009.

Lambert, F., Kug, J.-S., Park, P. J., Mahowald, N., Winckler, G., Abe-Ouchi, A., Oishi, R., Takemura, T., and Lee, J.-H.: The role of mineral-dust aerosols in polar temperature amplification, Nature Clim. Change, 3, 487-491, 2013.

Lau, K. M., Kim, K. M., Sud, Y. C., and Walker, G. K.: A GCM study of the response of the atmospheric water cycle of West Africa and the Atlantic to Saharan dust radiative forcing, Ann. Geophys., 27, 4023-4037, doi:10.5194/angeo-27-40232009, 2009.

Liao, H., Adams, P. J., Chung, S. H., Seinfeld, J. H., Mickley, L. J., and Jacob, D. J.: Interactions between tropospheric chemistry and aerosols in a unified general circulation model, J. Geophys. Res.-Atmos., 108, 4001, doi:10.1029/2001JD001260, 2003.

Liu, H., Jacob, D. J., Bey, I., and Yantosca, R. M.: Constraints from $210 \mathrm{~Pb}$ and ${ }^{7} \mathrm{Be}$ on wet deposition and transporting a global threee-dimensional chemical tracer model driven by assimilated meteorological fields, J. Geophys. Res., 106, 1210912128, 2001.

Liu, X. and Penner, J. E.: Ice nucleation parameterization for global models. Meteor. Z., 14, 499-514, 2005.

Mann, G. W., Carslaw, K. S., Ridley, D. A., Spracklen, D. V., Pringle, K. J., Merikanto, J., Korhonen, H., Schwarz, J. P., Lee, L. A., Manktelow, P. T., Woodhouse, M. T., Schmidt, A., Breider, T. J., Emmerson, K. M., Reddington, C. L., Chipperfield, M. P., and Pickering, S. J.: Intercomparison of modal and sectional aerosol microphysics representations within the same 3-D global chemical transport model, Atmos. Chem. Phys., 12, 4449-4476, doi:10.5194/acp-12-4449-2012, 2012.

Mahowald, N. M., Engelstaedter, S., Luo, C., Sealy, A., Artaxo, P., Benitez-Nelson, C., Bonnet, S., Chen, Y., Chuang, P. Y., Cohen, D. D., Dulac, F., Herut, B., Johansen, A. M., Kubilay, N., Losno, R., Maenhaut, W., Paytan, A., Prospero, J. A., Shank, L. M., and Siefert, R. L.: Atmospheric Iron Deposition: Global Distribution, Variability, and Human Perturbations, Ann. Rev. Mar. Sci., 1, 245-278, 2009. 
Marticorena, B. and Bergametti, G.: Modeling the atmospheric dust cycle: 1. Design of a soil-derived dust emission scheme, J. Geophys. Res., 100, 16415-16430, 1995.

Martonchik, J. V., Diner, D. J., Kahn, R., and Gaitley, B.: Comparison of MISR and AERONET aerosol optical depths over desert sites, Geophys. Res. Lett., 31, L16102, doi:10.1029/2004GL019807, 2004.

McConnell, C. L., Formenti, P., Highwood, E. J., and Harrison, M. A. J.: Using aircraft measurements to determine the refractive index of Saharan dust during the DODO experiments, Atmos. Chem. Phys., 10, 3081-3098, doi:10.5194/acp-8-30812010, 2010.

McKeen S. A., Wotawa G., Parrish D. D., Holloway J. S., Buhr M. P., Hubler G., Fehsenfeld F. C., and Meagher J. F.: Ozone production from Canadian wildfires during June and July of 1995, J. Geophys. Res., 107, 4192, doi:10.1029/2001JD000697, 2002.

Mian Chin, Diehl, T., Dubovik, O., Eck, T. F., Holben, B. N., Sinyuk, A., and Streets, D. G.: Light absorption by pollution, dust, and biomass burning aerosols: a global model study and evaluation with AERONET measurements, Ann. Geophys., 27, 3439-3464, doi:10.5194/angeo-27-3439-2009, 2009.

Mlawer, E. J., Taubman, S. J., Brown, P. D., Iacono, M. J., and Clough, S. A.: RRTM, a validated correlated-k model for the longwave, J. Geophys. Res., 102, 16663-16682, 1997.

Painter, T. H., Deems, J. S., Belnap, J., Hamlet, A. F., Landry, C. C., and Udall, B.: Response of Colorado River runoff to dust radiative forcing in snow, P. Natl. Acad. Sci. USA, 107, 1712517130, 2010.

Phillips, V. T. J., DeMott, P. J., and Andronache, C.: An empirical parameterization of heterogeneous ice nucleation for multiple chemical species of aerosol, J. Atmos. Sci., 65, 2757-2783, 2008.

Qian, Y., Flanner, M. G., Leung, L. Y. R., and Wang, W.: Sensitivity studies on the impacts of Tibetan Plateau snowpack pollution on the Asian hydrological cycle and monsoon climate, Atmos. Chem. Phys., 11, 1929-1948, doi:10.5194/acp-11-19292011, 2011.

Schell, B., Ackermann, I. J., Hass, H., Binkowski, F. S., and Ebel, A.: Modeling the formation of secondary organic aerosol within a comprehensive air quality modeling system, J. Geophys. Res., 106, 28275-28293, 2001.

Shao, Y.: A model for mineral dust emission, J. Geophys. Res., 106, 20239-20254, 2001.

Shao, Y., Fink, A. H., and Klose, M.: Numerical simulation of a continental-scale Saharan dust event, J. Geophys. Res., 115, D13205, doi:10.1029/2009JD012678, 2010.

Skamarock, W. C., Klemp, J. B., Dudhia, J., Gill, D. O., Barker, D. M., Duda, M. G., Huang, X., Wang, W., and Powers, J. G.: A description of the advanced research WRF version 3, NCAR Tech. Note, NCAR/TN-475+STR, 8 pp., Natl. available at: http: //www.mmm.ucar.edu/wrf/users/docs/arw_v3.pdf, Cent. for Atmos. Res., Boulder, CO, USA, 2008.

Sokolik, I. N., Winker, D. M., Bergametti, G., Gillette, D. A., Carmichael, G., Kaufman, Y. J., Gomes, L., Schuetz, L., and Penner, J. E.: Introduction to special section: Outstanding problems in quantifying the radiative impacts of mineral dust, J. Geophys. Res.-Atmos., 106, 18015-18027, 2001.

Solomos, S., Kallos, G., Kushta, J., Astitha, M., Tremback, C., Nenes, A., and Levin, Z.: An integrated modeling study on the effects of mineral dust and sea salt particles on clouds and precipitation, Atmos. Chem. Phys., 11, 873-892, doi:10.5194/acp11-873-2011, 2011.

Stauffer, D. R. and Seaman, N. L.: Use of four-dimensional data assimilation in a limited-area mesoscale model, Part I: Experiments with synoptic-scale data, Mon. Weather Rev., 118, 1250-1277, 1990.

Stockwell, W. R., Middleton, P., Chang, J. S., and Tang, X.: The second generation regional acid deposition model chemical mechanism for regional air quality modeling, J. Geophys. Res., 95, 16343-16367, 1990.

Tegen, I. and Fung, I.: Modeling of mineral dust in the atmosphere: Sources, transport, and optical thickness, J. Geophys. Res., 99, 22897-22914, 1994.

Tegen, I. and Lacis, A. A.: Modeling of particle size distribution and its influence on the radiative properties of mineral dust aerosol. J. Geophys. Res., 101, 19237-19244, doi:10.1029/95JD03610, 1996.

Tegen, I., Harrison, S. P., Kohfeld, K., Prentice, I. C., Coe, M., and Heimann, M.: Impact of vegetation and preferential source areas on global dust aerosol: Results from a model study, J. Geophys. Res.-Atmos., 107, 4576, doi:10.1029/2001JD000963, 2002.

Textor, C., Schulz, M., Guibert, S., Kinne, S., Balkanski, Y., Bauer, S., Berntsen, T., Berglen, T., Boucher, O., Chin, M., Dentener, F., Diehl, T., Easter, R., Feichter, H., Fillmore, D., Ghan, S., Ginoux, P., Gong, S., Grini, A., Hendricks, J., Horowitz, L., Huang, P., Isaksen, I., Iversen, I., Kloster, S., Koch, D., Kirkevåg, A., Kristjansson, J. E., Krol, M., Lauer, A., Lamarque, J. F., Liu, X., Montanaro, V., Myhre, G., Penner, J., Pitari, G., Reddy, S., Seland, Ø., Stier, P., Takemura, T., and Tie, X.: Analysis and quantification of the diversities of aerosol life cycles within AeroCom, Atmos. Chem. Phys., 6, 1777-1813, doi:10.5194/acp-61777-2006, 2006.

Thomson, M. C., Molesworth, A. M., Djingarey, M. H., Yameogo, K. R., Belanger, F., and Cuevas, L. E.: Potential of environmental models to predict meningitis epidemics in Africa, Trop. Med. Int. Health, 11, 781-788, 2006.

Van derWerf, G. R., Randerson, J. T., Giglio, L., Collatz, G. J., $\mathrm{Mu}$, M., Kasibhatla, P. S., Morton, D. C., DeFries, R. S., Jin, Y., and van Leeuwen, T. T.: Global fire emissions and the contribution of deforestation, savanna, forest, agricultural, and peat fires (1997-2009). Atmos. Chem. Phys., 10, 11707-11735, 10, doi:10.5194/acp-10-11707-2010, 2010.

Woodward, S.: Modeling the atmospheric life-cycle and radiative impact of mineral dust in the Hadley Centre climate model, J. Geophys. Res., 106, 18155-18166, 2001.

Yu, H., Remer, L. A., Chin, M., Bian, H., Tan, Q., Yuan, T., and Zhang, Y.: Aerosols from Overseas Rival Domestic Emissions over North America. Science, 337, 566-569, doi:10.1126/science.1217576, 2012.

Zaveri, R. A. and Peters, L. K.: A new lumped structure photochemical mechanism for large-scale applications, J. Geophys. Res., 104, 30387-30415, 1999.

Zaveri, R. A., Easter, R. C., Fast, J. D., and Peters, L. K.: Model for simulating aerosol interactions and chemistry (MOSAIC), J. Geophys. Res., 113, D13204, doi:10.1029/2007JD008792, 2008.

Zender, C. S., Bian, H., and Newman, D.: Mineral Dust Entrainment and Deposition (DEAD) model: Description 
and 1990s dust climatology, J. Geophys. Res., 108, 4416, doi:10.1029/2002JD002775, 2003.

Zhang, Y., Seigneur, C., Seinfeld, J. H., and Jacobson, M. Z.: Simulation of aerosol dynamics: a comparative review of algorithms used in air quality models, Aerosol Sci. Technol., 31, 487-514, 1999.

Zhang, Q., Streets, D. G., Carmichael, G. R., He, K. B., Huo, H., Kannari, A., Klimont, Z., Park, I. S., Reddy, S., Fu, J. S., Chen, D., Duan, L., Lei, Y., Wang, L. T., and Yao, Z. L.: Asian emissions in 2006 for the NASA INTEX-B mission, Atmos. Chem. Phys., 9, 5131-5153, doi:10.5194/acp-9-5131-2009, 2009.

Zhao, C., Wang, Y., Choi, Y., and Zeng, T.: Summertime impact of convective transport and lightning $\mathrm{NO}_{\mathrm{x}}$ production over North America: modeling dependence on meteorological simulations, Atmos. Chem. Phys., 9, 4315-4327, doi:10.5194/acp-9-43152009, 2009.

Zhao, C., Liu, X., Leung, L. R., Johnson, B., McFarlane, S. A., Gustafson Jr., W. I., Fast, J. D., and Easter, R.: The spatial distribution of mineral dust and its shortwave radiative forcing over North Africa: modeling sensitivities to dust emissions and aerosol size treatments, Atmos. Chem. Phys., 10, 8821-8838, doi:10.5194/acp-10-8821-2010, 2010.
Zhao, C., Liu, X., Leung, L. R., and Hagos, S.: Radiative impact of mineral dust on monsoon precipitation variability over West Africa, Atmos. Chem. Phys., 11, 1879-1893, doi:10.5194/acp11-1879-2011, 2011.

Zhao, C., Liu, X., and Leung, L. R.: Impact of the Desert dust on the summer monsoon system over Southwestern North America, Atmos. Chem. Phys., 12, 3717-3731, doi:10.5194/acp-12-37172012, 2012.

Zhao, C., Leung, L. R., Easter, R., Hand, J., and Avise, J.: Characterization of speciated aerosol direct radiative forcing over California, J. Geophys. Res., 118, 2372-2388, doi:10.1029/2012JD018364, 2013. 